\title{
Fixed-Route vs. Demand-Responsive Transport Feeder Services: An Exploratory Study Using an Agent-Based Model
}

\author{
Giovanni Calabrò $\left(\mathbb{D},{ }^{1}\right.$ Michela Le Pira $\left(\mathbb{D},{ }^{1}\right.$ Nadia Giuffrida $\left(\mathbb{D},{ }^{2}\right.$ Giuseppe Inturri ${ }^{(D},{ }^{3}$ \\ Matteo Ignaccolo $\mathbb{D}^{1}{ }^{1}$ and Gonçalo H. de A. Correia $\mathbb{D}^{4}$ \\ ${ }^{1}$ Department of Civil Engineering and Architecture, University of Catania, Catania 95123, Italy \\ ${ }^{2}$ School of Architecture, Planning and Environmental Policy, University College Dublin, \\ University College Richview Campus, D04 V1W8, Belfield, Dublin, Ireland \\ ${ }^{3}$ Department of Electric, Electronic and Computer Engineering, University of Catania, Catania 95123, Italy \\ ${ }^{4}$ Department of Transport \& Planning, Delft University of Technology, Stevinweg 1, 2628 CN, Delft, Netherlands \\ Correspondence should be addressed to Giovanni Calabrò; giovanni.calabro@unict.it
}

Received 4 August 2021; Revised 14 December 2021; Accepted 16 December 2021; Published 24 January 2022

Academic Editor: Rocío de Oña

Copyright (c) 2022 Giovanni Calabrò et al. This is an open access article distributed under the Creative Commons Attribution License, which permits unrestricted use, distribution, and reproduction in any medium, provided the original work is properly cited.

\begin{abstract}
Feeder transport services are fundamental as first and last-mile connectors of mass rapid transit (MRT). They are especially beneficial in low-demand areas where private transport is usually the main transport mode. Besides, the rapid spread of new technologies such as vehicle automation and the shared mobility paradigm gave rise to new mobility-on-demand modes that can dynamically match demand with service supply. In this context, the new generation of real-time demand-responsive transport services can act as on-demand feeders of MRT, but their performance needs to be compared with conventional fixed-route fixedschedule feeders. This article aims at presenting an agent-based model able to simulate different feeder services and explore the conditions that make a demand-responsive feeder (DRF) service more or less attractive than a fixed-route fixed-schedule feeder (FRF). The parametric simulation environment creates realistic constraints and parameters that are usually not included in analytical models because of high computational complexity. First, we identified the critical demand density representing a switching point between the two services. Once the demand density is fixed, exploratory scenarios are tested by changing the demand spatial distribution and patterns, service area, and service configurations. Main results suggest that the DRF is to be preferred when the demand is spatially concentrated close to the MRT station (e.g., in a TOD-like land-use area) or when station spacing is quite high (e.g., a regional railway service), whereas the FRF performs better when the demand is mainly originated at the MRT station to any other destinations in the service area (e.g., during peak hours). Besides, automated vehicles could play a role in reducing the operator cost if the service is performed with many small vehicles rather than higher-capacity vehicles, even if this would not imply a major benefit gain for the users.
\end{abstract}

\section{Introduction}

Transport systems are experiencing times of unprecedented changes. The push towards sustainable mobility and the advances in technology are changing both transport services and user habits [1]. Besides, the COVID-19 outbreak has heavily hit public transport (PT) and influenced travel behaviour with expected long-lasting impacts, especially at the urban level. In this changing environment, good planning and designing of transport systems become increasingly important to shape the future of urban regions [2]. Transport planning cannot ignore new trends and paradigms that are rapidly emerging, oriented towards the concept of sharing assets and services via ondemand services enabled by digital platforms. Mobility as a Service (MaaS) is one good example of such a new concept, being a digital platform enabling multimodal door-to-door trips via a single app that should aim at reducing private car usage (and eventually ownership) [3]. To achieve this goal, PT is considered to be the backbone of MaaS, complemented by mobility on-demand and shared modes [4]. 
In this context, demand-responsive transport (DRT) can play a fundamental role. Despite being an old concept that goes back as far as the end of the 90 s as "an intermediate form of PT, somewhere between a regular service route that uses small low floor buses and variably routed, highly personalised transport services offered by taxis" [5], it came back in the limelight in recent years mainly due to the spread of app-based ride-sharing systems such as Uber, Via, and Lyft (also known as transportation network companies).

However, the performance of these systems is often questioned especially concerning the transport demand they are meant to cover, the characteristics of the area, the topology of the road network in which they should operate, and the level of flexibility of the routes they follow. While they are often in competition with PT in the case of densely populated urban areas, they can potentially constitute a good solution to improve the accessibility to mass transit systems in the case of low-demand areas by covering the first-last mile of passenger PT trips [6]. The EU highlights how sparsely populated and underpopulated regions suffer from several structural problems such as lack of transport connections, few job opportunities, and inadequate social services [6]. In a recent publication by the European Parliament [7], the lack of accessibility to PT is considered one of the main issues faced by low-density and depopulated areas, with the consequent social exclusion of their inhabitants [8]. The strategic document underlines the role that DRT enabled by novel technologies could have in those regions as a result of its flexibility in meeting the demand. The document also notes that particular attention should be paid to its use in supplementing conventional PT such as train, metro, and trams that cannot reach all regions with the same coverage.

The conditions for DRT success have been explored in the literature focusing on some of the key aspects for PT system viability, for example, the demand patterns making DRT services more attractive than fixed scheduled ones [9], optimal fleet size [10], and fleet composition [11]. Currie and Fournier [12] showed that, statistically, high service costs are a major failure factor for DRT systems and that simpler operations (e.g., many-to-few or many-to-one, where ridership is concentrated at one of the two trip ends or close to it) had lower failure rates compared to more complex, difficult to manage, many-to-many service types. The use of DRT as a feeder of PT has the double advantage of serving the commuting demand of suburban areas and enhancing the ridership of PT, that is, ensuring at the same time wide coverage and high ridership at the expense of increasing the number of transfers (e.g., from bus to mass rapid transit (MRT)). Wang et al. [9] found that poor accessibility to PT fosters the introduction of DRT services to cover longdistance trips. Besides, accessibility, safety, and comfortrelated indicators should be considered to evaluate the satisfaction of PT users [13-15]. Real case studies (or pilots) involving DRT operations have been set up and investigated in the literature. However, they are inevitably influenced by the territorial context where they happen leading to results that are often difficult to generalize and thus transfer to other regions (e.g., [16, 17]). Analytical models have been typically used to find demand thresholds and switching points from one service to the other, as in, for example, the work by Quadrifoglio and Li [18].

Moreover, while the routing of these systems has long been addressed in the literature [19-21], the recent technological innovations in the trip booking processes have led to the emergence of new problems due to the need to guarantee dispatching of vehicles and requests in real time. These issues are amplified in the case of shared rides since different users might have different time schedules.

Finally, any analysis of these systems cannot ignore the technological evolution of the vehicles used. These seem to be oriented towards the conversion to full-electric ones and in the longer run to full automation [22].

Based on these premises, this article aims at proposing the use of an agent-based model $(A B M)$ to explore the performances of DRT in comparison with a fixed-route service as a feeder to mass transit. The authors began to address this issue in Calabrò et al. [23] by presenting and applying a new ABM to simulate adaptive flexible/fixed feeder services in a low-demand urban area in Catania (Italy). In this article, we upgrade the model also to verify current analytical models that aim at distinguishing DRT from fixed services [18]. Moreover, we extend such models introducing a nonuniform demand density and a variable vehicle capacity.

Our work tries to answer the two following research questions: how can flexible demand-responsive feeder transport services effectively match the demand with the supply in real time, aiming at maximizing shareability, minimizing the operator costs, and limiting passenger travel time? And under which conditions is it more convenient to adopt a fixed-route policy rather than a flexible one in providing feeder services towards mass rapid transit? In the process, we address several open research issues: (i) the transferability to different contexts by introducing a parametric design model; (ii) the booking process, by taking into account user-based time constraints in the dispatching algorithm; and (iii) the possibility to perform the service with automated vehicles, considering the impact they could have especially in terms of the operator cost.

The remainder of the article is organized as follows. The following section summarizes the literature on the DRT topic and highlights the current research gaps to be filled by this work. Section 3 presents the methodology, drawing an overview of the model with the dispatching algorithm and the selected output indicators. The model is then applied to a synthetic parametric application case, and the results for different scenarios are presented in Section 4. Finally, conclusions and discussion and future research are proposed in Section 5.

\section{Literature Review}

DRT planning and design has been addressed in literature mainly since the beginning of the 2000s (e.g., [24, 25]). A fair number of analytical models have been developed to face strategic planning decisions. In 2004, Diana and Dessouky [26] addressed the dial-a-ride problem with time windows introducing a new regret insertion heuristic able to face a 
large number of requests and outperform classical heuristics when a high-quality service (narrow time windows) is provided to the users. However, a door-to-door transport policy is assumed, while more trip shareability and travel time savings could be achieved by aggregating requests in virtual stops even if passengers would have to walk a short distance. Later in 2007, Quadrifoglio et al. [27] proposed an insertion heuristic for flexible services that merge the flexibility of DRT systems with the low-cost operation of fixedroute ones; the proposed service covers a specific geographic zone, with mandatory checkpoints located at major connection points or high-density demand zones. However, the model assumes that customers never reject the insertion proposed by the algorithm, so there is no negotiation phase between the system and the customers. In 2009, Quadrifoglio and $\mathrm{Li}$ [18] proposed a continuous approximation approach to compare the user-related performance of two operating strategies for a feeder bus service: fixed-route and demand-responsive. They provided approximate analytical solutions to estimate the critical demand density that allows a transit agency to switch between the two types of services. Chandra and Quadrifoglio [28] extended this model [18], using a gravity-based accessibility model to evaluate the accessibility impacts for first-/last-mile transport connectivity in the case of fixed-route transit and DRT, although using the same uniform demand across space. Other issues investigated through analytical models were fleet sizing based on a given quality of service for users [10], route design $[20,29]$, and the choice between different flexible transit strategies to accommodate a variable demand level [30], or estimating how user and operator costs vary according to the demand density, the service area [31], and the fleet size [32].

Analytical models can be considered design models that provide optimal solutions among infinite alternatives, thanks to introducing some approximations and simplifications within the model; such models are in general not capable of reproducing a complex reality without requiring enormous computation times; otherwise, it might be impossible to solve them analytically. In contrast, simulation models are ideal for reproducing the complexity of a system; once the input parameters are set, the simulation model runs a series of operations to the data whose number usually grows linearly with the size of the problem and can then generate several outputs, which can be used as key performance indicators of the system. In this respect, simulation models have been used extensively for making tactical and operational decisions regarding transport services in general and in particular for flexible transport services and last-mile connection [22, 33-36]. Winter et al. [11] designed, simulated, and tested an automated DRT for a campus-train station service; the simulation determined the optimal fleet size for the operation of the service and results showed the importance of adequate vehicle sizes and short vehicle dwell times. Scheltes and Correia [37] explored the use of automated vehicles as last-mile connection of train trips using an ABM. The ABM incorporated a dispatching algorithm distributing travel requests among the available vehicles using a first-comefirst-serve sequence. However, the type of service that was tested was conceived as being individual; therefore, it did not allow for shared trips among the passengers. Araldo et al. [38] studied the impact of consolidating the demand and limiting the density of waypoints locations through a modular simulation platform, searching for a trade-off between guaranteeing high quality of service for the users and providing a high-efficiency system; the model simulated different flexibility levels from door-to-door to buslike services. Oh et al. [39] proposed an agent-based simulation framework to evaluate the performance of an automated demand-responsive transit system as a complement and/or substitute to conventional mass transit. Their model suggests advantages in using higher-capacity vehicles rather than taxis, resulting in less travelled kilometres for the operator and less congestion. Fielbaum et al. [40] abandoned the door-to-door scheme showing that significant reductions in the vehicle-hours travelled and in the number of rejections can be achieved by asking travellers to walk a short distance to reach the assigned pick-up/ drop-off points. They proposed an insertion heuristic algorithm that encompasses and weighs both the travellers and the operator costs. The simulation was performed both on a toy grid network and the real case study of Manhattan. However, they considered neither the integration with PT nor a comparison with other forms of PT. In 2019, Inturri et al. [41] developed an ABM to compare the performance of a shared DRT with that of a taxi service [42] both for lowdemand areas and for fast-growing cities [43]. The results showed that DRT shared services are convenient under specific demand patterns for the analysed case studies. Based on these studies, Calabrò et al. [44] presented an $\mathrm{ABM}$ tailored to solve the last-mile problem of MRT in lowdemand areas, identifying optimal routes of feeder services.

Literature analysis shows that simulation models are not meant to provide optimal service design; they provide a good description of the performance of the system under specifically designed scenarios. Nevertheless, if the number of combinations between relevant parameters is not great and the simulation run time is not too long, it is possible to search the different configurations space in search for solutions that maximize or minimize a certain key performance indicator.

In this article, we present an $\mathrm{ABM}$, intending to integrate the benefits of the two methods: the model uses the simulation approach but on an ideal parameterizable environment so that the results are as scalable as possible. Based on $[18,23]$, the new ABM goes beyond a pure analytic model by proposing realistic and real-time dispatching algorithms, but without being tied to a specific simulation network neither to a particular case study, so its results are easily adaptable to other contexts using the main experimental parameters.

\section{Methodology}

Our research focuses on the first- and last-mile leg of PT trips, supposing that the PT backbone is a MRT network like rail or bus rapid transit (BRT). The transit agency might choose between the following two operational strategies: 
(1) A fixed-route feeder (FRF) service carried out by buses that pick-up and drop-off passengers at predetermined stops

(2) A demand-responsive feeder (DRF) service, where each vehicle builds customized routes to serve a group of passengers.

In our model, we assume that PT users choose between walking and using the feeder service to reach the MRT station. Although bikes and scooters (private or shared) can also be regarded as competitors to the proposed feeder system, we chose not to consider them in this first version of the model. In fact, we are interested in comparing the performance of FRF and DRF under different operating contexts, assuming that users have already chosen to use the bus as access/egress mode. Starting from this, the reliability of the two operational strategies should be considered the same, assuming an ideal scenario where all passengers are perfectly aware of the status of the system (e.g., real-time information sharing and no digital divide).

3.1. Overview of the Model. The main components of the simulation model are the service type (FRF or DRF), the geometric features of the service area, the demand model, the supply (vehicle) characteristics, and the simulation duration. The agents of the model are the travellers requesting a ride and the vehicles.

We consider that our feeder service operates in a rectangular area of length $L$ from the terminal station (horizontal direction) and width $W$ (vertical direction). The mobility demand follows a many-to-one/one-to-many pattern since the focus is on the first/last leg of an entire PT multimodal trip. A trip request can therefore have either origin or destination at the MRT station (the terminal), located on the left side of the service region. The value of $W$ can be considered the average distance between the terminal and the MRT stations upstream and downstream. Hereinafter, we will refer to the passengers originating at the terminal as egress passengers, while the passengers having destination at the terminal will be referred to as access passengers.

From a spatial perspective, the base demand density $\lambda$ (in trips $/ \mathrm{km}^{2} \mathrm{~h}$ ) is modelled as a linear function of the horizontal distance $x$ from the terminal that is analytically derived in Appendix A. By varying the slope of the demand decay function, we reproduce different types of urban density and land use.

Each trip request $i$ involves a group of a number $G_{i}$ of travellers. We assume that $G_{i}$ follows a geometric distribution. If we denote with $p_{1}$ the probability that request $i$ consists of a single user $\left(\operatorname{Pr}\left(G_{i}=1\right)\right)$; therefore, the probability that the group is constituted by $k$ users is given by

$$
\begin{aligned}
\operatorname{Pr}\left(G_{i}=k\right) & =p_{k} \\
& =p_{1}\left(1-p_{1}\right)^{k-1} .
\end{aligned}
$$

If the Manhattan distance (i.e., the distance measured along axes at right angles) $d_{T, i}$ between the user's origin and the MRT station (access leg) or the MRT station and the destination (egress leg) is lower than a minimum threshold $d_{0}$, a user is assumed to walk directly to/from the station. Otherwise, the probability of choosing the feeder service rapidly increases with $d_{T, i}$ and is given by the attractiveness coefficient $\eta \in[0,1]$ we introduced as follows:

$$
\eta=1-e^{-0.5\left(\left(d_{T, i}-d_{0}\right)^{2} / \gamma^{2}\right)}
$$

where $\gamma$ is a parameter that rules the increase in attractivity of the feeder service due to the distance from the station: the lower the value of $\gamma$, the higher the speed at which $\eta$ increases with $d_{T, i}$. Figure 1 shows a graphical representation of $\eta$ across the service area.

As in [18], the fraction of trips having the MRT station as the destination is given by the parameter $\alpha \in[0,1]$, so the proportion of users going from the station to a destination inside the service area is $(1-\alpha)$. Although the Poisson process is well suited for the former, the temporal distribution of the egress passengers is strongly related to the schedule of the MRT line. However, assuming that the headway of the MRT line is small enough (i.e., less than 5 minutes) in both directions, we believe that the Poisson distribution with rate parameter $\lambda$ is a reasonable approximation and should marginally affect the results.

Regarding the supply side, the vehicles (buses, minibuses, vans, or automobiles) are defined by three input parameters: the number of vehicles $n_{V}$ composing the fleet, the cruising speed $v$, and the allowed capacity in available seats in each vehicle cap.

Finally, the duration of the simulation ST, in which the input parameters are unchanged, should be sufficiently high to ensure that the steady state is reached and that the results are marginally affected by the warm-up period.

3.2. The Fixed-Route Feeder. The FRF (Figure 2) runs back and forth on a straight line from the MRT station to the farthest bus stop, with spacing $d_{s}$ (input parameter) between the stops.

Assuming ideal conditions (no congestion or other disturbance to the service), the maximum cycle time $\mathrm{CT}_{\max }$, that is, the time needed for a vehicle (bus) to complete the round trip, is the sum of two components (adapted from [18]), which is given as

$$
\mathrm{CT}_{\max }=\frac{2\left(L-\left(d_{s} / 2\right)\right)}{v}+\left(\frac{2 L}{d_{s}}-1\right) \cdot\left(\tau_{s}+\tau_{p}\right),
$$

where the first component is the ratio between the length of a complete cycle and the bus cruising speed $v$, and the second one estimates the dwell time at each stop $\tau_{s}$, including the time of acceleration and braking, and the additional dwell time due to boarding/alighting passengers $\tau_{p}$.

The headway between two vehicles is given by

$$
h=\frac{\mathrm{CT}_{\max }+\tau_{t}}{n_{V}},
$$

where $\tau_{t}$ is the minimum dwell time required at the terminal. 


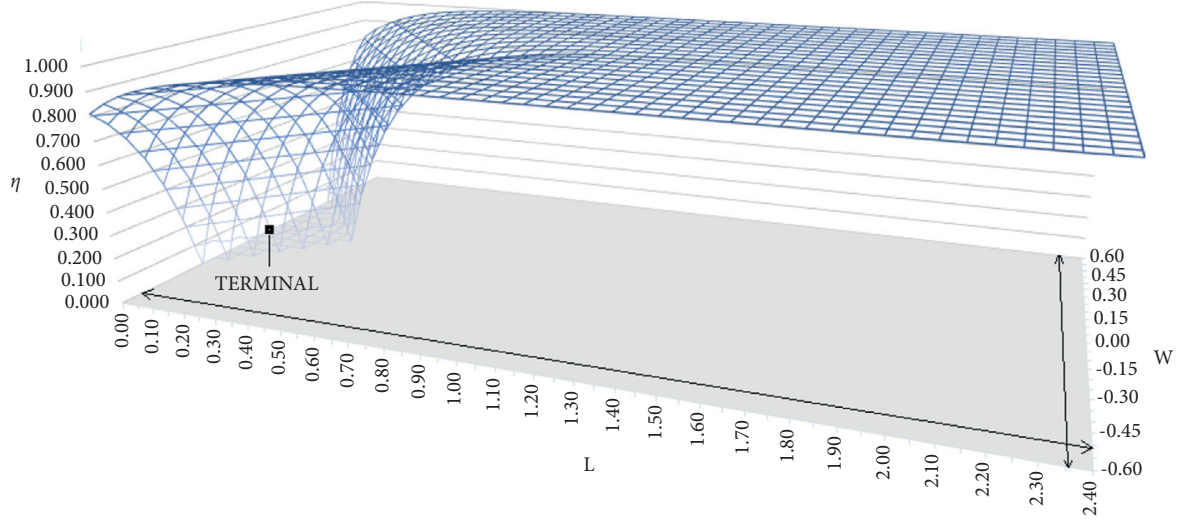

Figure 1: Values of the attractiveness coefficient across a service area with $L=2.4 \mathrm{~km}$ and $W=1.2 \mathrm{~km}$. In this example, we set $\gamma=d 0=0.3 \mathrm{~km}$. From a temporal point of view, the demand follows a Poisson process with $\lambda$ as the rate parameter.

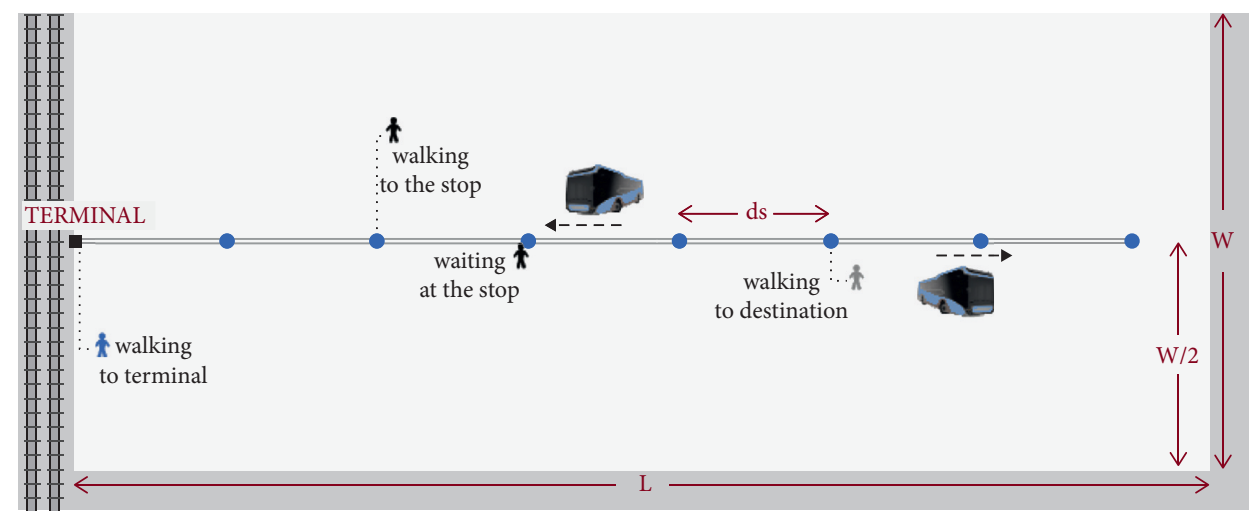

FIGURE 2: Scheme of the FRF service: users in black are about to take the bus, users in grey got off the bus, and the user in blue is walking directly to the terminal.

Egress passengers originate at the MRT station, take the bus with the earliest departure time, alight at the desired stop (i.e., the closest one to the destination of the trip) during the first half of the cycle, and walk to their final destination.

Access passengers originate in the service area, walk to the closest stop, wait for the first bus headed to the terminal, travel onboard, and finally alight at the MRT station.

We assume that a traveller is aware of the expected waiting time at the stop thanks to a real-time information system by the feeder service provider. Therefore, if the expected waiting time is above a certain maximum waiting time $t_{w \text {, max }}$ (input parameter), traveller $i$ assumes the status "rejected" and walks to the station. Instead, if the overall travel time overcomes the latest drop-off time interval at the station $l d_{i}$, the passenger assumes the status of "delayed." This threshold varies according to the different time tolerance of the users, as shown in the following equation:

$$
l d_{i}=\min \left\{t_{w, \max }+\left(1+\delta_{i}+\gamma_{i}\right) \frac{d_{T, i}}{v},\left(1+\gamma_{i}\right) \frac{d_{T, i}}{v_{p}}\right\},
$$

where $\delta_{i}=d_{T, i} /(L+W / 2)$ relates the travellers' distance to the maximum one to reach the terminal (based on the farthest user that could be generated in the service area) and represents the willingness to deviate from the shortest path based on his/her distance to the terminal; $\gamma i \in[0,1]$ aims at reproducing travellers' individual willingness to deviate based on the trip purpose, and $v_{p}$ is the walking speed since Equation (5) also takes into account the walking time from origin to destination.

Fleet size, vehicle capacity, and cruising speed are set at the beginning of the simulation. Each vehicle is generated at the terminal stop (i.e., the MRT station). The fixed feeder vehicle travels along the route until it reaches a stop. Passengers at their destination stop alight while waiting travellers board the vehicle (if in the inbound direction), following the first-come-first-served (FCFS) queue rule, and only if the passenger group size is not greater than the available seats.

3.3. The Demand-Responsive Feeder. The DRF (Figure 3) travels along a grid street network, with spacing $d_{g}$ between the streets. Vehicle routes are dynamically created based on users' requests, and each intersection can act as a potential access/egress location for a traveller (virtual stop).

Unlike in the FRF case, choosing the headway of the DRF is not straightforward. While the flexibility of the DRF implies that vehicles could leave the station when they are full, in the case of a feeder service it could be better to assume a given headway to assure service regularity and synchronization with the MRT. In fact, the length of the full cycle 


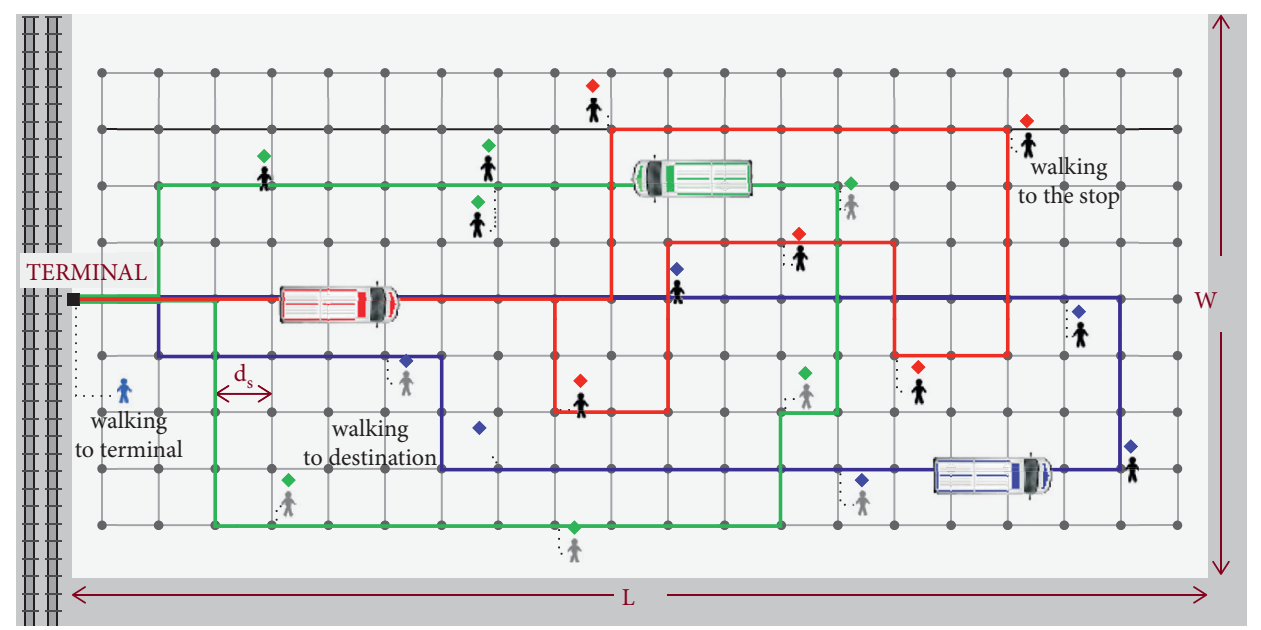

FIGURE 3: Scheme of the DRF service: users in black are waiting for the assigned vehicle, users in grey have left the vehicle and are walking to their destination, and the user in blue is walking directly to the terminal.

route and the cycle time depend on the expected number of requests $n$ that the vehicle should serve along that route, which in turn depends on the headway, as shown in the following equation:

$$
\begin{aligned}
n & =n_{u} \sum_{k=1}^{\infty} \frac{p_{k}}{k} \\
& =\bar{\lambda} \mathrm{LWh} \sum_{k=1}^{\infty} \frac{p_{k}}{k},
\end{aligned}
$$

where $n_{u}$ is the number of users generated during the time interval of duration $h$. We point out that $n \leq n_{u}$ because a single trip request can involve $k$ users (see equation (1)).

A rough approximation of the expected cycle distance ECD, that is the length of the round route, can be estimated based on $n$ (Equation (6)) and is given by the sum of a horizontal component (the vehicle movement from left to the right and vice versa) and a vertical component (the deviations along the vertical direction to serve the passengers). For the analytical derivation of ECD, the reader is referred to Appendix B.

Finally, the headway of the DRF can be derived from the expected cycle time (ECT) and the fleet size as follows:

$$
\begin{aligned}
h & =\frac{\mathrm{ECT}+\tau_{T}}{n_{V}} \\
& =\frac{(\mathrm{ECD} / v)+\left(\xi_{c} \tau_{s}+\tau_{p}\right) n+\tau_{T}}{n_{V}} .
\end{aligned}
$$

Equation (7) is nonlinear (as ECD depends on $h$ ), so we choose an initial value $h^{*}$ of the headway, compute $n$, ECD, and ECT using Equations (6) and (7), calculate the new value of $h$, and then repeat the process for an adequate number of iterations until convergence. This procedure takes place in the "setup" phase, before each simulation starts.

The requests for the DRF service are processed in real time through a dispatching algorithm that assigns the traveller to a vehicle and a virtual stop (either a pick-up or drop-off location), according to the user time windows and the vehicle available seats, based on the FCFS rule. If no feasible match can be found, the user assumes the status "rejected" and walks directly to the destination. In this way, the penalty due to the rejection is not an arbitrary fixed value, as done, for example, in [41], but is directly related to the walking time from the origin to the destination, under the simplification that the rejected user does not have any other modal choices. This implies that rejecting requests involving longer trips plays a significant role in increasing the average user disutility (they will have to walk more to the station or from the station). Figure 4(a)illustrates the dynamics for a DRF passenger, from the trip request moment to the arrival at the destination, whereas Figure 4(b) shows the vehicle state chart.

Let us define the set of egress passengers as $E$ and the set of access passengers as $A$. Egress passengers are assumed to make the trip request as soon as they show up at the terminal, so they are readily available to use the DRF service. Access passengers, instead, need to be given enough time to reach the assigned pick-up location and cannot be served before the earliest pick-up time interval $e p_{i j}$, which is formulated as follows:

$$
e p_{i j}= \begin{cases}0, & \text { if } i \in E, \\ w k_{i j}+\tau_{w k}, & \text { if } i \in A,\end{cases}
$$

where $w k_{i j}$ is the walking time needed for passenger $i$ to reach the pick-up location $j$ and $\tau_{w k}$ is a fixed extra time to account for the variability of walking time implying the risk of late arrival at the stop (it can be reasonably set to 1 minute).

When making a trip request, users should specify the latest pick-up time interval $l p_{i}$ they are willing to accept. Once again, this threshold is slightly different for egress and access passengers. The former has to wait for the DRF vehicle at the terminal, so they are supposed to be less tolerant towards the waiting time than the latter, who can generally wait at home or the workplace. The $l p_{i}$ is computed as follows: 


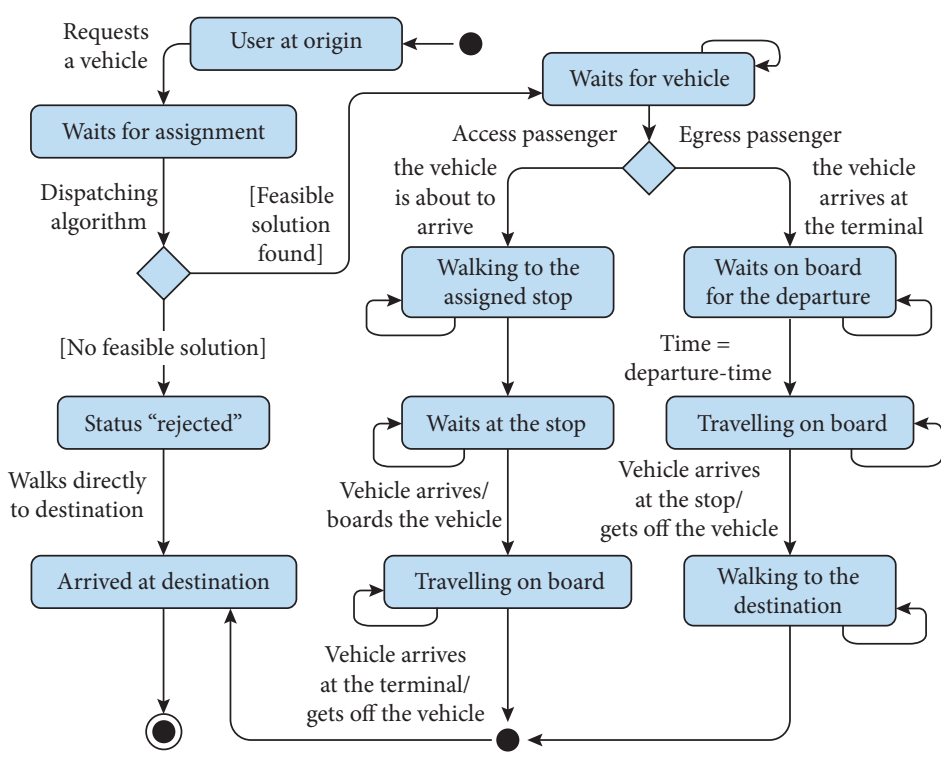

(a)

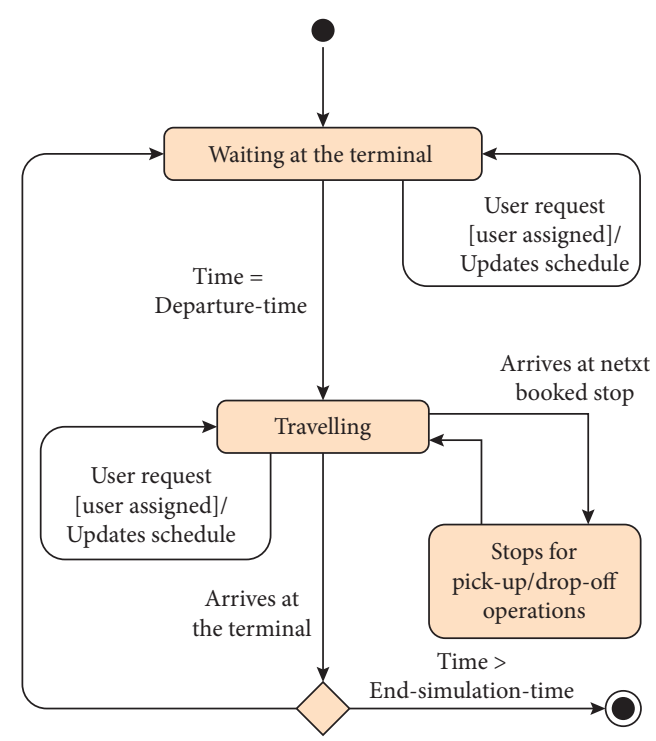

(b)

FIgURE 4: State charts for the DRF feeder service: (a) passenger state chart and (b) vehicle state chart.

$$
l p_{i}= \begin{cases}t_{w, \text { max }}, & \text { if } i \in E, \\ \left(1+\gamma_{i}\right) t_{w, \text { max }}, & \text { if } i \in A,\end{cases}
$$

where the time tolerance level is ruled by the coefficient $\gamma_{i}$ introduced in Equation (5).

The last component of the user time windows is the latest drop-off time interval $l d_{i}$, already introduced with the FRF service. This formulation is slightly different, since the term $t_{w \text { max }}$ is replaced by $l p_{i}$, as follows:

$$
l d_{i}=\min \left\{l p_{i}+\left(1+\delta_{i}+\gamma_{i}\right) \frac{d_{T, i}}{v},\left(1+\gamma_{i}\right) \frac{d_{T, i}}{v_{p}}\right\} \text {. }
$$

3.4. The Dispatching Algorithm for the DRF. Every time a new trip request $i$ (consisting of a user or group of users) occurs, the optimal matching between the demand (users group requesting the trip) and the supply (vehicle fleet) is carried out by the dispatching algorithm (Figure 5). As in [23], our algorithm follows an insertion heuristic approach (An insertion heuristic approach is adopted because it is widely used in practice to solve transportation scheduling problems, as it often provides very good solutions compared to optimality, it is computationally fast, and it can easily handle complicating constraints [20].), involving three levels of exploration of the feasible solutions:

(i) The set of routes $r \in R$, that is, the sequence of already scheduled stops (to be) visited by the vehicles $(0,1, \ldots, p, p+1, \ldots, m, 0)$ where 0 refers to the terminal. Note that each route corresponds to a complete cycle.

(ii) The set of possible virtual stops for the new passenger $s \in S$. (iii) The set of feasible insertions of the request in the route schedule between two already scheduled stops $(p, p+1) \in r$.

When determining $R$ for a new trip request $i$, the algorithm first includes the vehicle routes of the current service cycle. In case no feasible insertion is found, $R$ is updated including the vehicles' route schedule of the next cycle. In this way, the possibility of rejection is reduced.

The algorithm only considers the nearest three intersections to the user's origin (or destination), plus the nearest already scheduled virtual stop, so to limit the vehicles' detour from the original route. This implies a maximum of four possible stops, which is important to limit the length of $S$, especially in very "dense" street networks and reduce the computational time. Moreover, through this approach, we keep constant the maximum number of candidates and unbind the time complexity of the algorithm from the granularity of the street network.

For each $r \in R$ and each $s \in S$, the algorithm repeats the procedure of inserting $s$ between $p$ and $p+1$ for each $p=p^{*}$, $\ldots, m$, where $p^{*}$ is the first not yet visited stop of $r$, verifying that the following constraints are satisfied and computing the cost of the insertion.

The first constraint to be met is that the time $t_{s}$ at which the vehicle $v$ will stop at $s$ must be consistent with the time windows of the newly arrived user group $i$, as defined by Equations (8)-(10). This can be expressed as follows:

$$
\begin{cases}t_{0}<t_{s} \leq l d_{i}, & \text { if } i \in E, \\ e p_{i} \leq t_{s} \leq l p_{i}, & \text { if } i \in A .\end{cases}
$$

The second constraint is related to the departure time $t_{0}$ from the terminal and to the expected cycle time (ECT) (see (7)), as shown as follows: 


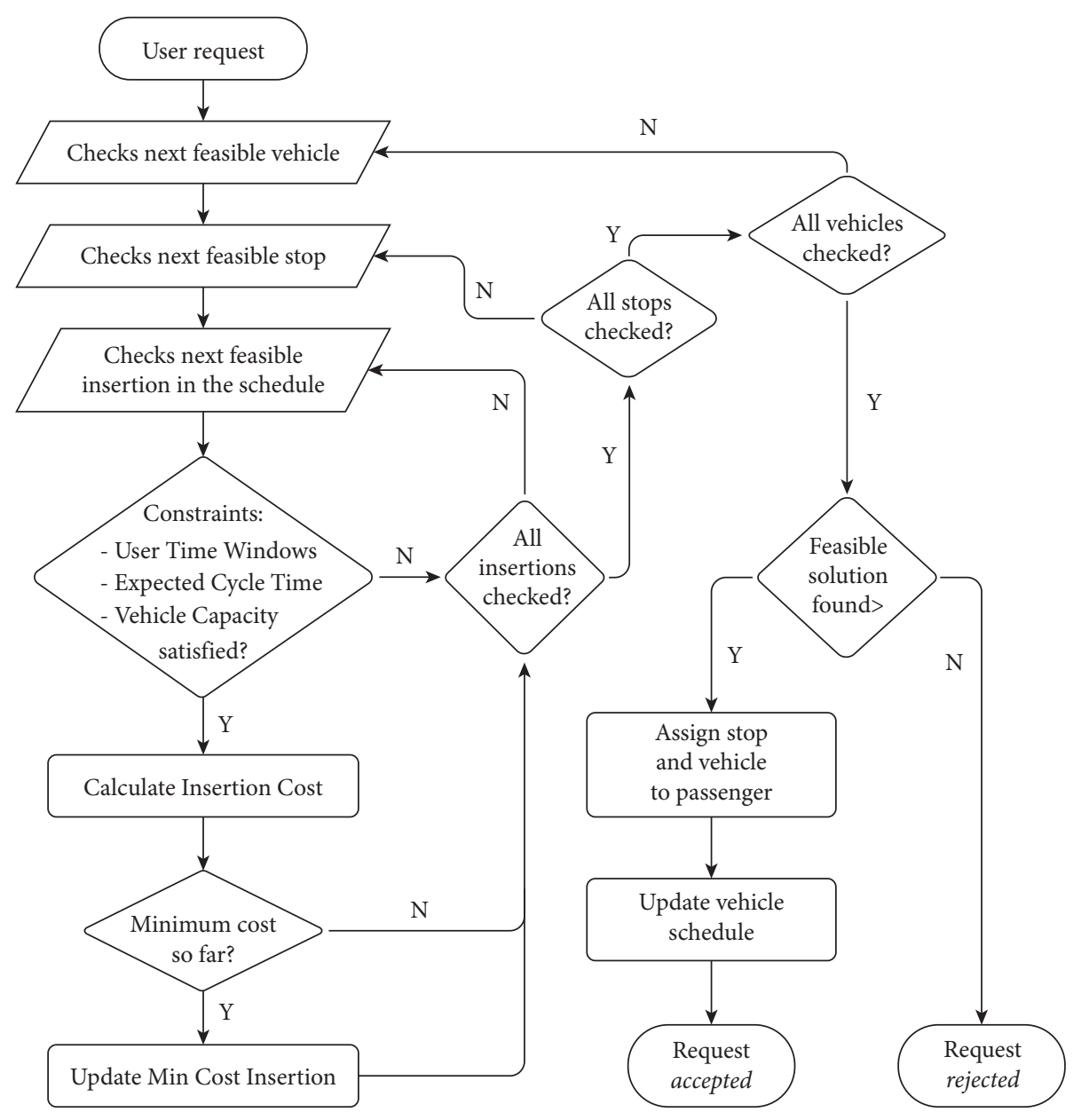

FIgURE 5: Flowchart of the dispatching algorithm for the DRF service.

$$
\begin{cases}0<t_{0} \leq l p_{i}, & \text { if } i \in E, \\ t_{s}<t_{0}+\mathrm{ECT} \leq l d_{i}, & \text { if } i \in A .\end{cases}
$$

Finally, the third constraint imposes that the number of passengers on board $\left(\operatorname{load}_{v, s}\right)$ when vehicle $v$ stops at $s$ must not exceed the vehicle capacity, as expressed by the following relation:

$$
\operatorname{load}_{v, s} \leq \text { Cap. }
$$

If all the constraints are met, the cost function of inserting $s$ into $r$ between $p$ and $p+1$ is inspired by [40] and is computed as the sum of the cost $c_{i}$ for the user (group of users) $i$ to be inserted, the additional cost $\Delta c_{d}$ for the passengers who are delayed because of the insertion, and the cost $\Delta c_{o}$ for the operator due to the detour.

$\operatorname{cost}(r, s, p)=c_{i}(r, s, p)+\Delta c_{d}(r, s, p)+\Delta c_{o}(r, s, p)$.

Equations (15)-(17) show the three components of the cost function, expressed in terms of time. The cost for the user group is given by the weighted sum of the three components of the travel time minus the ride time related to the shortest path from/to the terminal (since it is not affected by the optimization procedure), multiplied by the number of users in the group $G_{i}$ (see equation (1)) making the request, which is given as

$$
\begin{aligned}
c_{i}(r, s, p)= & G_{i}\left(w_{w k} t_{w k, i}(s)+w_{w t} t_{w t, i}(r, p)\right. \\
& \left.+w_{r d}\left(t_{r d, i}(r, s, p)-\frac{d_{T, i}}{v}\right)\right) .
\end{aligned}
$$

Where $w_{w k}, w_{w t}$, and $w_{r d}$ are weighting coefficients related to the walking, waiting, and ride time, respectively. The additional costs depend on the detour time $\Delta t_{r}$ caused by the insertion of $s$ in $r$, which is given as

$$
\begin{aligned}
\Delta c_{d}(r, s, p)= & \left(w_{r d} n_{r d, d}(r, p)\right. \\
& \left.+w_{w t} n_{w t, d}(r, p)\right) \Delta t_{r}(r, s, p)
\end{aligned}
$$

where $n_{r d, d}$ is the number of passengers on board affected by the detour, $n_{w t, d}$ is the number of users who will have to wait an extra $\Delta t_{r}$ at the stop due to the schedule update, and $w_{o}$ is the weighting coefficients of the additional cost caused by the detour for the operator, related to the vehicle-kilometres travelled. After having examined all the feasible solutions (if any), the insertion heuristic chooses the assignment that minimizes the cost function, which is shown as follows: 


$$
\min _{r \in R ; s \in S ; p \in r}\{\operatorname{cost}(r, s, p) \quad \text { s.t. Equations } 11-13\} .
$$

Regarding the time complexity of the insertion heuristic, considering the "first level" of exploration of the feasible solution, the size of the set of feasible routes $r$ is linearly related to the fleet size $n_{V}$. It is an input parameter, but it should be properly chosen based on the expected number of requests $n$ to serve (imagine having no constraints on $n_{V}$ ). If $n$ is sufficiently high, $n_{V}$ is linearly related with $n$. The second level regards the potential stops $s$ to associate with the user request. As already explained, we chose to limit the number of feasible stops to a maximum of four. Finally, in the third level, the number of feasible insertions in the vehicle schedule $(m+1)$ is also linearly related to $n$. Based on these considerations, the time complexity of our insertion heuristic is $O\left(n^{2}\right)$, for each new request. This means that the matching process between passengers and vehicles requires low computational efforts and takes place dynamically, in real time, even with a high number of requests per unit of time.

3.5. Output Indicators. The model results can be assessed through different output indicators [41] to compare the two feeder services: FRF and DRF as shown in Tables 1 and 2.

Another indicator that encompasses both the user and operator point of view is the so-called total unit cost (TUC). It is based on [41] and is equal to the sum of the passenger unit cost (PUC) and the operator unit cost (OUC), which is given as

$$
\mathrm{TUC}(€ / \mathrm{pax})=\mathrm{PUC}+\mathrm{OUC},
$$

where

$$
\begin{aligned}
\operatorname{PUC}\left(\frac{€}{\operatorname{pax}}\right) & =\left[w_{w k}\left(T_{w k}+T_{r e j}\right)+w_{w t} T_{w t}+w_{r d} T_{r d}\right] \cdot \mathrm{VoT}, \\
\operatorname{OUC}(€ / \operatorname{pax}) & =\frac{D \cdot C_{k m}+n_{V} \cdot \mathrm{ST} \cdot C_{h}}{N_{U} \cdot \mathrm{ACP} \cdot(1-\mathrm{WLK})} .
\end{aligned}
$$

Here, VoT $(€ / h)$ is the value of time for the travellers, $C_{k m}(€ /$ veh $\mathrm{km})$ the distance-related operator cost, $C_{h}(€ /$ veh h) the hourly driver cost, and $S T(h)$ the total simulation time. For the first test, VoT was estimated to be $10 € / \mathrm{h}$, while regarding the operator-related costs, we set $C_{h}=25 € /$ veh $h$ and $C_{k m}$ ranging from 0.5 to $0.1 € /$ veh $\mathrm{km}$ according to the vehicle size (distance-related operator cost $\left(C_{K m}\right)$ : automobile 4 pax $0.1 € /$ veh $\mathrm{km}$; minivan $6 / 8$ pax $0.25 € / \mathrm{veh} \mathrm{km}$; minibus 9 seats ( 20 pax) $0.5 € / v e h \mathrm{~km}$.). It is worthy of notice that in the case of a service performed by automated vehicles, the second term of the OUC would be equal to zero since no drivers are considered.

\section{Application of the Model with Different Parameters}

The model described above is programmed in the NetLogo development environment [45]. The operation parameters of the feeder services can be varied, as already depicted in
Figures 2 and 3. This approach provides the advantage of obtaining useful insights for a transit agency operating in different urban contexts and under different demand patterns. Moreover, it is easy to perform a broad range of sensitivity analyses regarding the main input parameters of the system, which are outlined as follows:

(i) Geometric: length $L$ and width $W$ of the service area, the distance between stops $d_{s}$ (for the FRF) and grid street spacing $d_{g}$.

(ii) Service: type of service (FRF/DRF), total simulation time $S T(h)$, and headway $h(\mathrm{~min})$.

(iii) Supply: number of operating vehicles $n_{V}$, vehicle average speed $S(\mathrm{~km} / \mathrm{h})$, the maximum seat capacity cap of a vehicle.

(iv) Demand: average demand density $\bar{\lambda}$ (pax/h), trip direction coefficient $\alpha$, demand decay coefficient $\Lambda$ (ratio between demand density at $x=0$ and at $x=L$ ), probability of having one user per request $p_{1}$, maximum waiting time $t_{w t \text {, max }}(\min )$, and maximum walking distance $d_{w k, \max }$.

(v) Cost: weighting coefficients related to the passenger $w_{w k}, w_{w t}, w_{r d}$, and the operator $w_{o}$.

\subsection{First Set of Simulations: Finding the Critical Demand} Density. We first show the effectiveness of the simulation model and the proposed insertion heuristic by reproducing the scenarios described by Quadrifoglio and Li [18]. Following this approach, we computed the disutility function $U$ for the FRF and the DRF services under increasing demand levels and keeping supply, cost, and geometric parameters fixed. The critical demand density $\lambda_{c}$ is calculated as the one that provides an equal passengers' disutility for the two services. The simulation input parameters are simulation time $S T=8 \mathrm{~h}$, service area dimensions $L=3.2 \mathrm{~km}$ and $W=0.8 \mathrm{~km}$, grid spacing $d_{g}=0.1 \mathrm{~km}$, trip direction coefficient $\alpha=0.5$, and demand decay coefficient $\Lambda=1$ (spatially uniform demand). The input parameters used for the simulations are listed in Table 3, where the abbreviation Sc-A1 refers to a one-vehicle case and Sc-A2 to a two-vehicle case. To better reproduce the assumptions made by Quadrifoglio and Li [18], we chose sufficiently high values of $t_{w t \text {, max }}$ and cap to relax the passenger time windows and to assume an unlimited vehicle capacity, respectively.

Besides, we set up a new scenario (Table 3, Sc-Base) able to better exploit the novelty of our methodology and include the "real-world" constraints of the DRF operations (passenger time windows, vehicle capacity, maximum cycle time, etc.) that were not considered in [18]. Sc-Base also served as a reference scenario against which to compare other $10 \mathrm{op}-$ erational scenarios (as shown in the next subsections) and thus perform a sensitivity analysis of the most significant input parameters. For each scenario, 25 simulation runs have been performed to have a statistic of events.

The results of the first set of simulations in terms of average disutility and TUC are reported in Figures 6 and 7. 
TABle 1: Description of the user-related output indicators.

\begin{tabular}{|c|c|c|}
\hline Indicator & Abbreviation & Description/formulation \\
\hline \#Users & NU & Total number of travellers generated during the simulation \\
\hline$\%$ Walking Users & WLK & Percentage of users who do not request for the feeder service and walk to/from the terminal \\
\hline $\begin{array}{l}\% \text { Accepted } \\
\text { Passengers }\end{array}$ & $\mathrm{ACP}$ & Percentage of travellers using the feeder service \\
\hline$\%$ Rejected Requests & REJ & Percentage of travellers whose trip request was rejected \\
\hline $\begin{array}{l}\text { \% Delayed } \\
\text { Passengers }\end{array}$ & DEL & Percentage of users who are delayed beyond the time windows \\
\hline Avg pretrip time $[\mathrm{s}]$ & $\mathrm{TPT}^{*}$ & $\begin{array}{c}\text { Average time that elapses between when a user makes the trip request (and is accepted) and starts } \\
\text { walking to the stop }\end{array}$ \\
\hline $\begin{array}{l}\text { Avg walking time } \\
{[\mathrm{s}]}\end{array}$ & TWK & $\begin{array}{c}\text { Average time for a user of the feeder service walking from the origin to the stop or from the stop to the } \\
\text { destination }\end{array}$ \\
\hline Avg waiting time $[\mathrm{s}]$ & TWT & Average time that a traveller waits at the stop for the vehicle \\
\hline Avg ride time $[\mathrm{s}]$ & TRD & Average \\
\hline $\begin{array}{l}\text { Avg total travel time } \\
{[\mathrm{s}]}\end{array}$ & $\mathrm{T}$ & Average total travel time, which is the sum of the following components: $\mathrm{T}=\mathrm{TWK}+\mathrm{TWT}+\mathrm{TRD}$ \\
\hline Rejection penalty $[\mathrm{s}]$ & Trej & Total walking time related to rejected travellers divided by the total number of passengers. \\
\hline Avg time stretch & STR & $\begin{array}{l}\text { Average ratio, for all passengers, between } \mathrm{T} \text { and the sum of the ride and walking time if using the } \\
\text { shortest path (no waiting time). }\end{array}$ \\
\hline Avg disutility [min] & $\mathrm{U}$ & $\begin{array}{c}\text { As defined in [18], it is the weighted sum of TWK, TWT, and TRD considering the weighting } \\
\text { coefficients of equation (16) }\end{array}$ \\
\hline
\end{tabular}

* Only for the DRF service.

TABLE 2: Description of the operator-related output indicators.

\begin{tabular}{|c|c|c|}
\hline Indicator & Abbreviation & Description/formulation \\
\hline Tot. Driven distance $[\mathrm{km}]$ & $\mathrm{D}$ & Total distance travelled by the vehicles during the simulation time \\
\hline $\begin{array}{l}\text { Tot. energy consumption } \\
\text { [kWh] }\end{array}$ & TEC & $\begin{array}{l}\text { Total energy used by the vehicles during the simulation time (energy consumption (EC): } \\
\text { automobile } 4 \text { pax } 0.18 \mathrm{kWh} / \mathrm{km}(\text { range } 250 \mathrm{~km}) \text {-minivan } 6 / 8 \mathrm{pax} 0.3 \mathrm{kWh} / \mathrm{km} \text { (range } 200 \mathrm{~km}) \text { - } \\
\text { minibus } 9 \text { seats }(20 \mathrm{pax}) 0.6 \mathrm{kWh} / \mathrm{km}(\text { range. } 120-150 \mathrm{~km}) \mathrm{https} / / \text { www.bluebus.fr/ } \\
\text { caracteristiques-techniques-electric bus } 50 \text { seats } 1 \mathrm{kWh} / \mathrm{km}(\text { range. } 120 \mathrm{~km}) \mathrm{https} / / \mathrm{www} \text {. } \\
\text { sustainable-bus.com/news/electric-bus-range-focus-on-electricity-consumption-a-sum-up/): } \\
\text { TEC }=D \cdot \mathrm{EC}\end{array}$ \\
\hline $\begin{array}{l}\text { Avg vehicle occupancy } \\
{[\operatorname{pax}]}\end{array}$ & AVO & Average number of passengers per vehicle \\
\hline $\begin{array}{l}\text { Transport intensity } \\
{[\mathrm{km} / \mathrm{pax}]}\end{array}$ & TI & Average distance travelled by the service per transported passenger $\mathrm{TI}=\mathrm{D} /(\mathrm{NU} \bullet \mathrm{ACP})$ \\
\hline Commercial speed $[\mathrm{km} / \mathrm{h}]$ & $v_{c}$ & \\
\hline$\%$ Stopping time & ST & $\begin{array}{l}\text { Ratio between the total time spent by vehicles at the terminal or the stops and the simulation } \\
\text { time }\end{array}$ \\
\hline
\end{tabular}

TABLE 3: Input parameters adopted for the first set of simulated scenarios.

\begin{tabular}{|c|c|c|c|c|}
\hline \multirow{2}{*}{ Parameter } & \multirow{2}{*}{ Abbreviation } & \multicolumn{3}{|c|}{ Values } \\
\hline & & Sc-A1 & Sc-A2 & Sc-base \\
\hline Stop spacing $[\mathrm{m}]$ & $d_{\mathrm{s}}$ & 490 & 490 & 425 \\
\hline Average demand density $\left[\mathrm{pax} / \mathrm{km}^{2} \mathrm{~h}\right]$ & $\bar{\lambda}$ & $5-30$ & $20-40$ & $5-60$ \\
\hline $\operatorname{Pr}\left(G_{i}=k\right)$ group probability & $p_{1}$ & 1.0 & 1.0 & 0.8 \\
\hline Maximum waiting time [min] & $t_{w, \max }$ & 30 & 30 & 10 \\
\hline Walking speed $[\mathrm{m} / \mathrm{s}]$ & $v_{p}$ & 0.9 & 0.9 & 1.0 \\
\hline Vehicle cruising speed $[\mathrm{km} / \mathrm{h}]$ & $\stackrel{p}{v}$ & 32.0 & 32.0 & 30.0 \\
\hline Vehicle capacity [pax] & Cap & 50 & 50 & 20 \\
\hline Number of vehicles & $n_{V}$ & 1 & 2 & 3 \\
\hline \multirow{3}{*}{ Headway [min] } & h & 20 & 10 & 7 \\
\hline & $\mathrm{h}$ & $17-30$ & $10-20$ & 7 \\
\hline & $w_{w t}$ & 1 & 1 & 2 \\
\hline \multirow{3}{*}{ Cost coefficients [-] } & $w_{w k}$ & 3 & 3 & 2 \\
\hline & $w_{r d}$ & 2 & 2 & 1 \\
\hline & $w_{o}$ & 0 & 0 & 4 \\
\hline
\end{tabular}




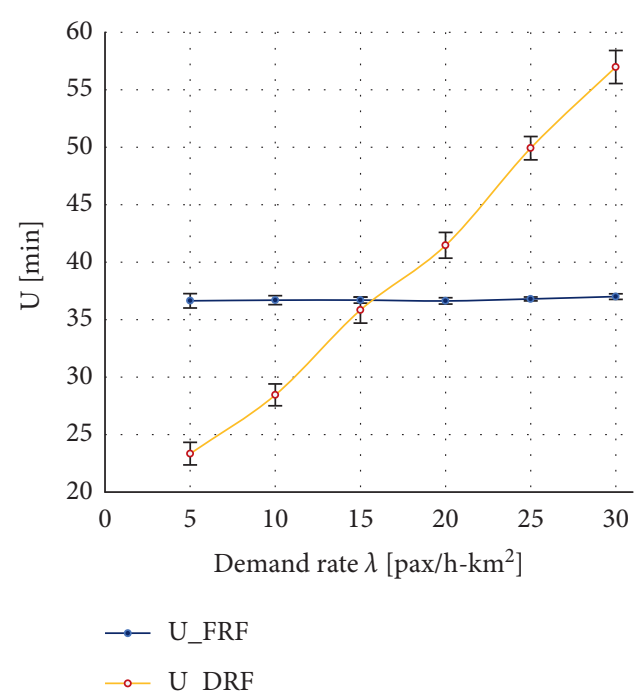

(a)

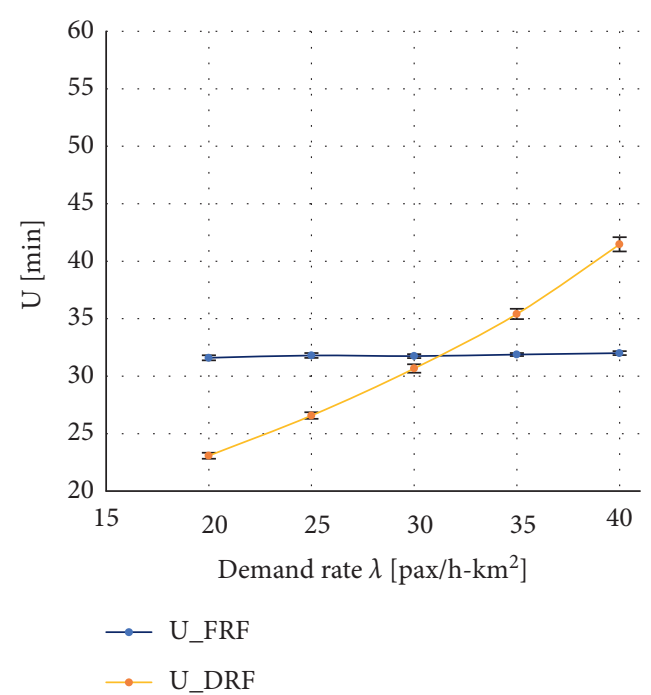

(b)

Figure 6: Disutility of Sc-A1 (a) and Sc-A2 (b) (bars showing confidence intervals).

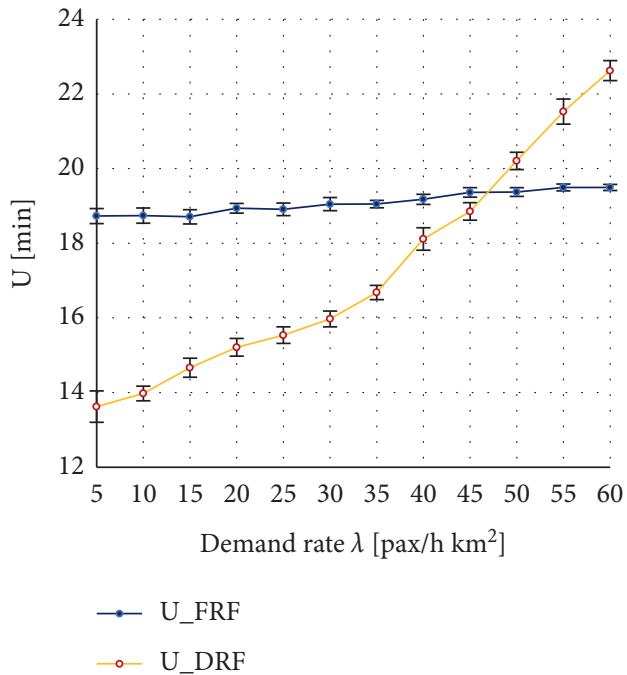

(a)

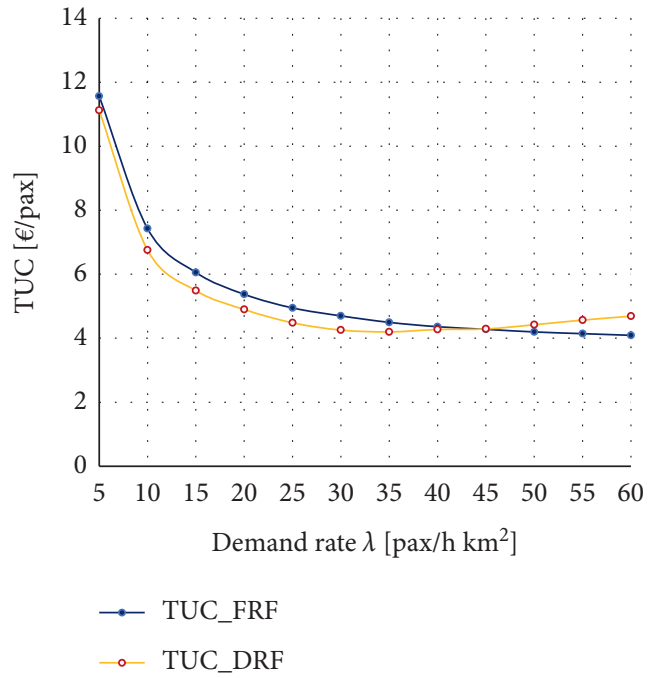

(b)

Figure 7: Performance of the Sc-base scenario in terms of user disutility (a) and transport unit cost (b) (bars in (a) showing confidence intervals).

Sc-A1 (Figure 6(a)) and Sc-A2 (Figure 6(b)) find the critical demand density of $15 \mathrm{pax} / \mathrm{h}-\mathrm{km}^{2}$ for the 1 -vehicle case and $30 \mathrm{pax} / \mathrm{h}-\mathrm{km}^{2}$ for the 2-vehicle case, respectively, a little bit higher than the $12 \mathrm{pax} / \mathrm{h}-\mathrm{km}^{2}$ and $28 \mathrm{pax} / \mathrm{h}-\mathrm{km}^{2}$ found by the analytical model of Quadrifoglio and $\mathrm{Li}$ [18]. This is probably due to the capability of the simulation model to reproduce a more efficient vehicle dispatching and routing for the DRF service, thus enlarging its range of performance.

This is even more clear from the results of the Sc-base (Figure 7(a)), obtained by removing the constraints corresponding to the analytical model, where the switching point for the passenger convenience shifts in the range between 45 and $50 \mathrm{pax} / \mathrm{h}-\mathrm{km}^{2}$. However, by looking at the TUC (Figure 7(b)), which is an indicator of system efficiency including also the operator point of view, the threshold is lower, between 40 and $45 \mathrm{pax} / \mathrm{h}-\mathrm{km}^{2}$. This is imputable to the fast increase in the DRF supply cost (distance travelled) for a higher demand rate.

As expected, the disutility for the FRF travellers, as opposed to the DRF ones, is not very sensitive to the demand density variation. This can be ascribed to the regularity of the service since the average ride time is almost the same for travellers, and the headway (affecting the average waiting time at stops) as well as the walking time, which only depends on $W, d_{s}$, and $v_{p}$, is constant. In particular, in Figure 7(a), one can notice a small increase in $U$ with the demand density due to the increasing number of passengers and vehicles causing higher idle times at stops. 
According to the results, we fixed the demand density to the critical value of $40 \mathrm{pax} / \mathrm{h}-\mathrm{km}^{2}$ and performed a second set of simulations to assess the attractiveness of the two services by varying the other model parameters.

4.2. Second Set of Simulations: Testing Different Demand/ Service Configurations. Several scenarios have been defined to reproduce different use cases by varying the following:

(1) Demand spatial distribution (Sc-1): from uniform (Sc-base) to trapezoidal (Sc-1a) or triangular (Sc-1b); the first one might represent a residential area, whereas the other two might mimic a TOD-like land-use area, where the demand progressively decreases from the MRT station to the outskirt.

(2) Demand O/D pattern (Sc-2): from uniform $(\alpha=0.5)$ of the Sc-base, to more concentrated demand patterns to/from the MRT station $(\alpha=0.9, \mathrm{Sc}-2 \mathrm{a} ; \alpha=0.1$, Sc-2b). This allows mimicking different demand configurations according to both land use and temporal demand distribution. Sc-base is more representative of (i) a mixed land-use area with balanced trips from and to the MRT station, or (ii) a mono-functional land-use area during off-peak hours (e.g., a residential area). Both Sc-2a and Sc-2b might represent mono-functional land-use areas during peak hours. The former is a residential area during the "morning peak" period or a workplace/ service area during the "evening peak" period and the opposite applies to the latter.

(3) Area stretching (Sc-3): modifying the ratio L/W from 4 (Sc-base) towards less-/more-stretched areas (L/W equal to 2 or 3 , for Sc-3a and Sc-3b, and 6 for Sc-3c). This represents different MRT services according to the station spacing (from $0.6 \mathrm{~km}$ to $1.2 \mathrm{~km}$ ), for example, from an urban metro service to a regional railway service.

(4) Vehicle capacity (Sc-4): increasing the number of vehicles of smaller capacity, from 3 vehicles of 20 seats (Sc-base) to 5 vehicles of 8 seats (Sc-4a), 10 vehicles of 4 seats (Sc-4b), and 20 vehicles of 2 seats (Sc-4c). This allows testing different types of flexible feeders, from those performed by minibuses or vans to a ride-sharing service with small vehicles (e.g., UberX Share).

The ten simulated scenarios (each one involving 25 simulation runs) are synthetically described in Table 4 concerning the Sc-base. All the other input parameters are set equal to those of Sc-base, as reported in Table 3. The main results are reported and commented in the next subsections. The results of the two services will be first separately presented; then, a comparison between them is performed. From the point of view of the demand, we focus on PUC, from the point of view of the operator on OUC, whereas TUC encompasses both points of view. An overview of scenario results with all the output indicators defined in Tables 1 and 2 is presented in Appendix E.
4.2.1. Fixed-Route Feeder. The results of the simulations for the FRF in terms of PUC, OUC, and $U$ are reported in Figure 8.

As expected, the operator cost OUC is quite constant over scenarios Sc-1 and Sc-2 because the fixed service is not affected by the spatiotemporal demand distribution, while Sc-3a provides a smaller operation cost because of the shorter travelled distance.

If we look at demand spatial distribution (Sc-1), when demand is higher near the MRT station, the TUC of the FRF remains almost the same $(+1 \%)$. We report a reduction of PUC of $3 \%$ (SC-1a) and 7\% (Sc-1b) when compared to a uniform demand distribution (Sc-base). This is mainly due to shorter passenger ride times since they are more concentrated near the MRT station. On the other hand, the OUC increases, since fewer travellers are using the feeder service.

Interesting results emerge if we consider different demand patterns (Sc-2). In particular, there are two opposite trends: a higher concentration of users directed to the MRT station (Sc$2 \mathrm{a})$ worsens the performance of the FRF in terms of PUC (+9\%) and, thus, TUC (+7\%), whereas the opposite occurs when users originate mostly at the MRT station (with multiple destinations) $(-7 \%,-5 \%)$. This could be explained in terms of the regularity of the service. In the first case, bus bunching might occur, thus worsening the headway regularity and average waiting times. Conversely, the regularity improves in the opposite case (Sc-2b) because passengers are generated mostly at the MRT station and board the FRF with scheduled departure times.

A different configuration of the service area (more or less stretched) leads to different results. In particular, there is a decreasing trend of PUC (and TUC) from less-stretched to more-stretched areas with the best result for Sc-3c. This outcome was expected as well since walking time is more relevant for users than the other time components. In this respect, a more-stretched area implies shorter walking times and higher ride time.

4.2.2. Demand-Responsive Feeder. Figure 9 reports the results from DRF simulations, similar to the FRF case.

Demand spatial distribution and, in particular, a demand concentrated closer to the MRT station (Sc-1) improves the performance of DRF compared to Sc-base, also because of better dispatching of passengers that can be more easily assigned to a few virtual stops. As in the previous case, the decrease in PUC (-2\% in Sc-1a and $-13 \%$ in Sc-1b) is compensated by the increase in OUC $(+14 \%$ and $+28 \%$, respectively).

Interesting and quite different results compared to the FRF case emerge if we consider different demand patterns (Sc-2). In particular, it is possible to see a lower performance of the DRF in Sc-2 compared to the Sc-base. More specifically, the worst case occurs in Sc-2b, that is, when the demand is mainly originated at the MRT station. This can be ascribed to higher waiting times at the station, since "waiting" starts once the demand is generated (vs. the "home"-based demand where it starts when the user arrives at the virtual stop). Therefore, demand concentration worsens the DRF. Besides, in Sc-2a, a higher number of rejected users $(+141 \%$ higher than in the Sc-base) occur. This result can be explained by a 
TABLE 4: Description of the second set of simulated scenarios.

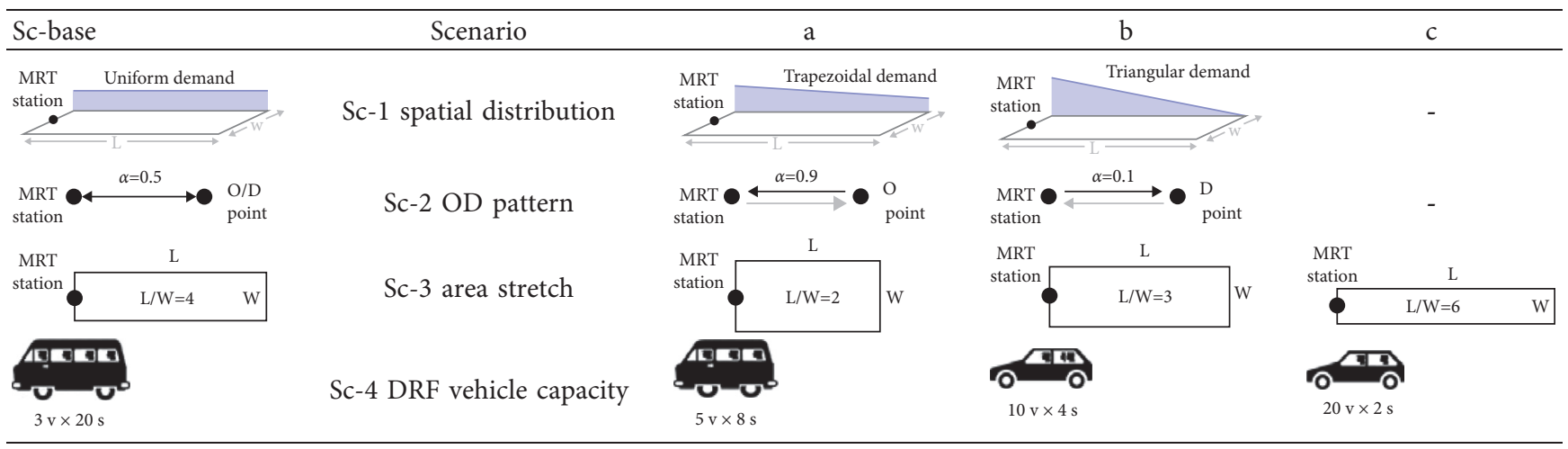

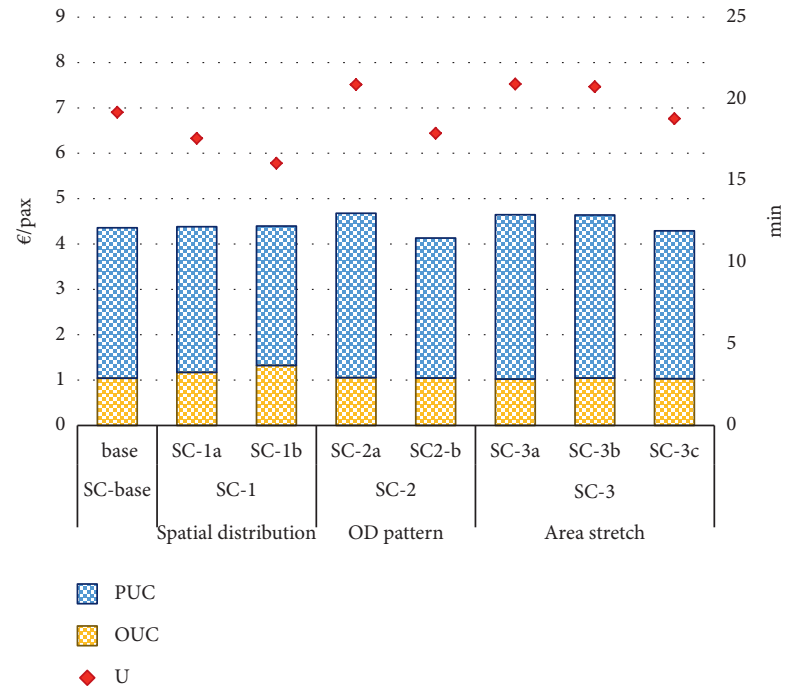

FIGURE 8: Results of the second set of simulations for the FRF (for result interpretation; $\mathrm{PUC}=$ passenger unit cost; $\mathrm{OUC}=$ operator unit cost; $\mathrm{U}=$ utility).

simpler assignment of passengers to vehicles in the case of one origin and multiple destinations (one-to-many) than in the opposite case (many-to-one).

Three more scenarios are simulated for the DRF case, that is, by varying the number and capacity of vehicles while keeping the total seat capacity constant (Sc-4). A clear increasing trend of TUC is visible due to higher OUC once the number of vehicles and drivers increases. Interestingly, PUC decreases from Sc-base to Sc-4, but the relative difference between the subscenarios is very low. This suggests that it is neither profitable nor beneficial to use a higher number of small vehicles (i.e., cars) to perform the DRF service (Sc-4b, Sc$4 c$ ), while vans might represent a good compromise. They would be a suitable solution from the user perspective while implying higher operator cost $(+35 \%)$ but resulting in a slightly lower TUC $(-4 \%)$ compared to the minibuses case of Sc-base.

This result confirms the impact of driver costs on the total operator cost and suggests the possibility of looking at automated vehicles (AV) as a potential solution. Figure 10 shows a comparison between TUC with and without the driver cost for Sc-base and Sc-4 showing how the difference between the two values increases with the number of

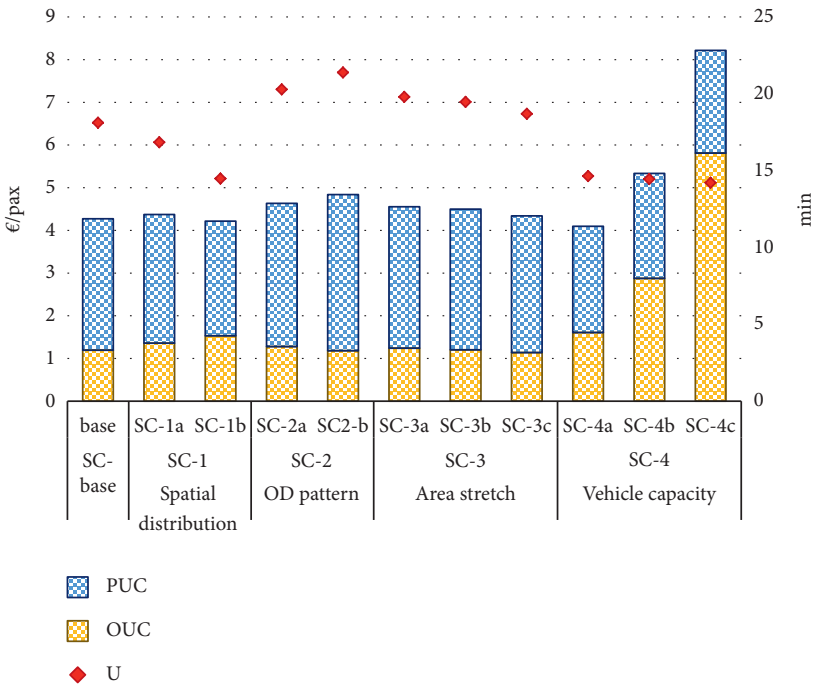

FIgURE 9: Results of the second set of simulations for the DRF (for result interpretation; $\mathrm{PUC}=$ passenger unit cost; $\mathrm{OUC}=$ operator unit cost; $\mathrm{U}=$ utility).

vehicles. Clear savings can be obtained in the case of Sc-4c, implying 20 vehicles of 2 seats, that is, a Uber-like service. However, this option should be analysed more in detail by looking at other important variables like the cost of AVs and the different operation conditions (e.g., road infrastructure, commercial speed, increased road congestion) and the willingness of passengers to use them.

4.2.3. DRF vs. FRF. Figure 11 shows the comparison between the DRF and the FRF. This analysis allows finding what service suits better to each situation.

In general, the DRF performs better in Sc-1b where we have a decreasing demand from the MRT station to the outskirts, thanks to the flexibility of the service, which allows a better matching between passengers and vehicles and lower driving distances.

There is no clear trend in varying the shape of the service area. The two services are almost equivalent in Sc-3a, Sc-3b, and $\mathrm{Sc}-3 \mathrm{c}$ where a better performance for the users is compensated by higher costs for the operator (and vice versa). By stretching the area ( $\mathrm{Sc}-3 \mathrm{c})$, thus representing different catchment areas according to the MRT network (in 


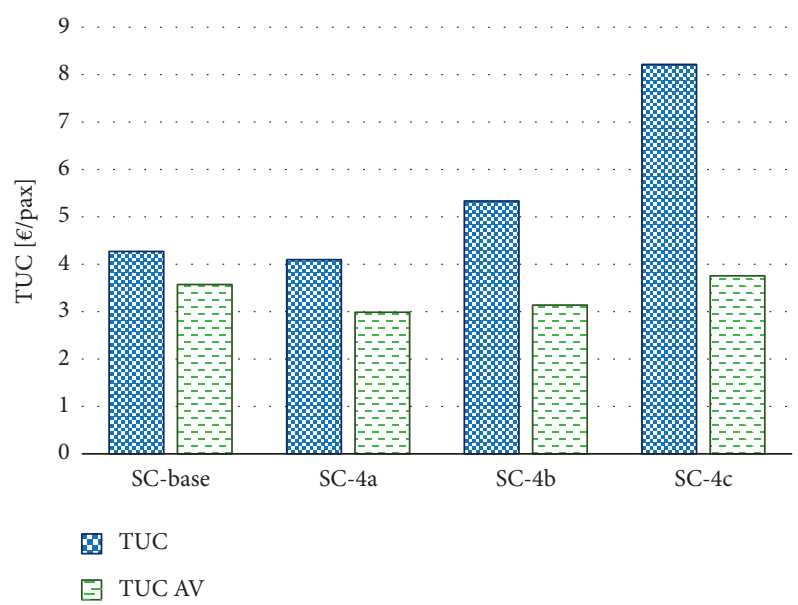

FigURe 10: Comparison between transport unit cost (TUC) for traditional and automated vehicles (AV) in Scenario Base (2 vehicles with capacity $=20$ seats) and Scenario 4 (vehicle capacity $\mathrm{x}$ number of vehicles $=8 \times 5,4 \times 10,2 \times 20$ ).

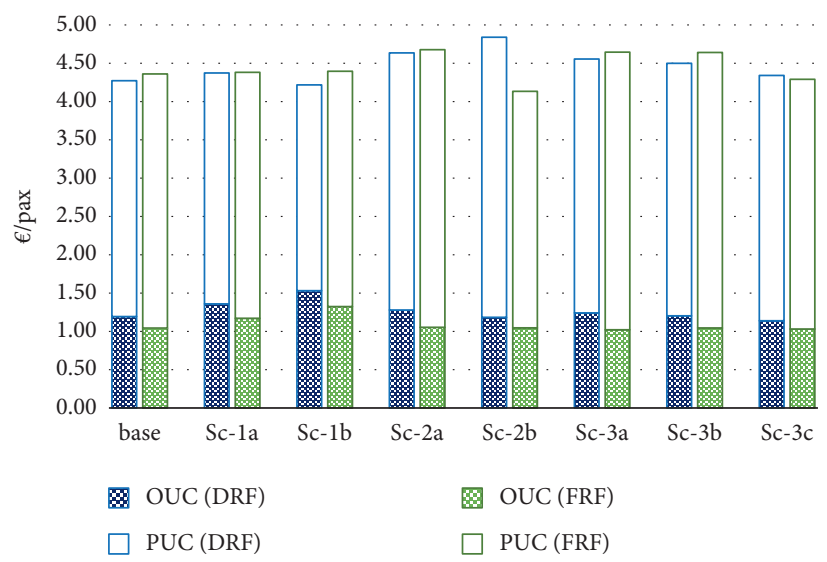

FIGURE 11: Comparison between the DRF and the FRF in different scenarios (for result interpretation; PUC=passenger unit cost; OUC $=$ operator unit cost).

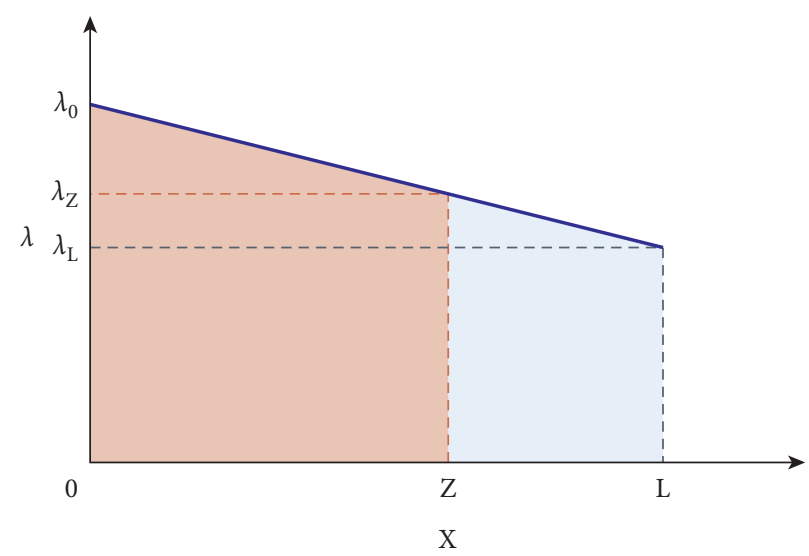

Figure 12: A general trend of the demand density along $(x)$ (for the interpretation of the references to colour in this figure legend, the reader is referred to the web version of this article).

terms of the station and line spacing), the FRF starts becoming more attractive than the DRF.

Demand pattern is a critical issue to consider when planning and designing feeder services (Sc-2). In this respect, the simulation results suggest adopting the FRF instead of the DRF when the demand is mainly originated at the MRT station (to multiple destinations) and vice versa, since this would imply smaller TUC, especially in the first case (Sc-2b). 


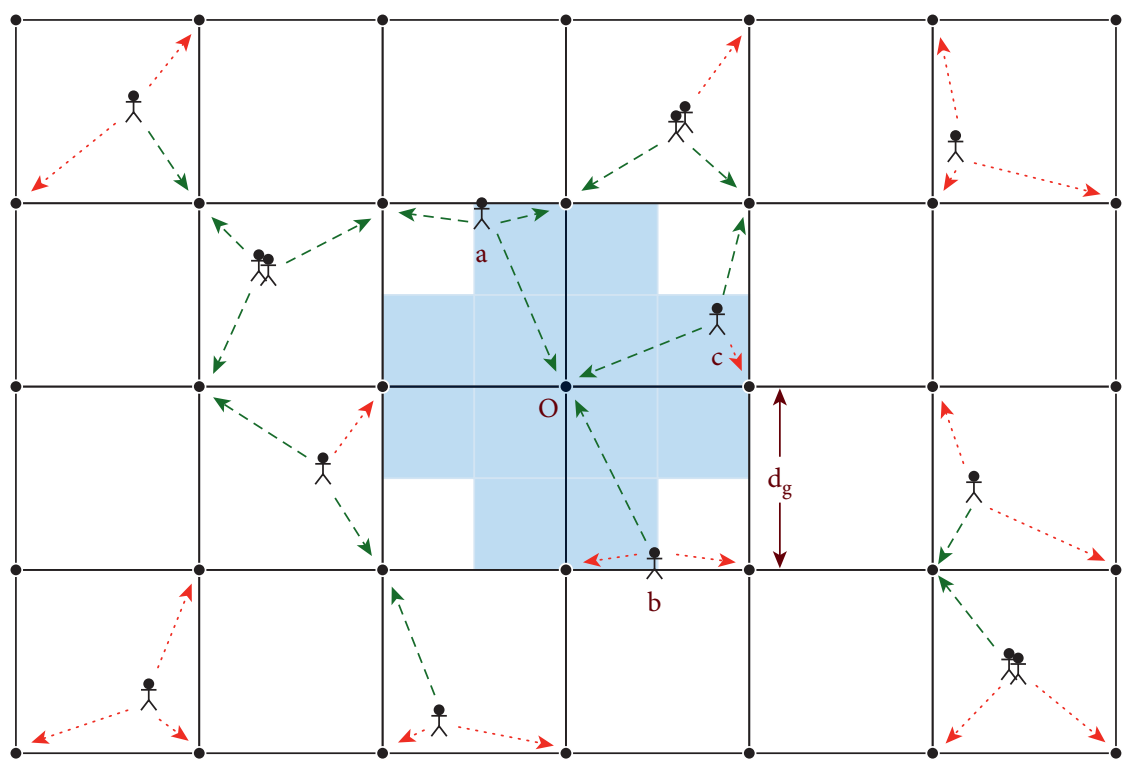

FIGURE 13: Possible options of demand consolidation at virtual stops. (For the interpretation of the references to colour in this figure legend, the reader is referred to the web version of this article.).

\begin{tabular}{|c|c|c|c|c|c|c|c|c|}
\hline \multirow{2}{*}{ OUTPUT } & \multirow{2}{*}{$\begin{array}{c}\text { SC-base } \\
\text { base }\end{array}$} & \multicolumn{2}{|c|}{ SC-1 } & \multicolumn{2}{|c|}{ SC-2 } & \multicolumn{3}{|c|}{ SC-3 } \\
\hline & & SC-1a & SC-1b & SC- $2 a$ & SC2-b & SC-3a & SC-3b & $\mathrm{SC}-3 \mathrm{C}$ \\
\hline \multicolumn{9}{|l|}{ USER-RELATED } \\
\hline \# tot Requests (NR) & 820 & $0 \%$ & $0 \%$ & $0 \%$ & $0 \%$ & $1 \%$ & $0 \%$ & $1 \%$ \\
\hline \% Walking Users (WLK) & 7.50 & $135 \%$ & $260 \%$ & $11 \%$ & $2 \%$ & $32 \%$ & $16 \%$ & $3 \%$ \\
\hline \% Accepted Requests (PAX) & 99.86 & D $0 \%$ & $\times 0 \%$ & 区 $-1 \%$ & $\triangle 0 \%$ & D $0 \%$ & D $0 \%$ & 区 $0 \%$ \\
\hline \% Rejected Requests (REJ) & 0.14 & D-13\% & 区 $41 \%$ & メ $443 \%$ & $D-96 \%$ & $D-100 \%$ & D-64\% & 区 $296 \%$ \\
\hline \% Delayed Requests (DEL) & 4.78 & 区 $58 \%$ & Х $112 \%$ & 区 $34 \%$ & D-17\% & 凶 $117 \%$ & $\times 86 \%$ & D-10\% \\
\hline Avg Walking Time (Twk) [min] & 4.98 & $\mathrm{X} 1 \%$ & Х $2 \%$ & 凶 $0 \%$ & $\mathbf{1} \%$ & 区 $37 \%$ & (x) $20 \%$ & D-17\% \\
\hline Avg Waiting Time (Twt) [min] & 1.92 & D $-2 \%$ & D $-5 \%$ & 区 $69 \%$ & D $-76 \%$ & D $-20 \%$ & D $-5 \%$ & 区 $13 \%$ \\
\hline Avg Ride Time (Trd) [min] & 6.10 & D-11\% & D $-25 \%$ & [D $-14 \%$ & 区 $24 \%$ & D-17\% & $\triangle-2 \%$ & 区 $13 \%$ \\
\hline Avg Total Travel Time (T) [min] & 12.99 & $-5 \%$ & $\triangle-11 \%$ & 区 $4 \%$ & 凶 $0 \%$ & 区 $3 \%$ & x $6 \%$ & 凶 $1 \%$ \\
\hline Avg Time Stretch (STR) & 1.61 & $\mathbf{X}_{2 \%}$ & 凶5\% & Х $4 \%$ & D-1\% & D $-8 \%$ & D-3\% & 凶 7\% \\
\hline Avg Passenger Disutility (Upax) & 19.18 & $D-8 \%$ & $D-16 \%$ & $\times 9 \%$ & D-7\% & 凶 $9 \%$ & 区 $8 \%$ & D-2\% \\
\hline Passenger Unit Cost (PUC) [€/pax] & 3.32 & $D-3 \%$ & D $-7 \%$ & $\times 9 \%$ & D-7\% & $凶 9 \%$ & $凶 8 \%$ & D-2\% \\
\hline \multicolumn{9}{|l|}{ OPERATOR-RELATED } \\
\hline Total Driven Distance (D) $[\mathrm{Km}]$ & 381.33 & メ $0 \%$ & $凶 0 \%$ & $凶 0 \%$ & $凶 0 \%$ & D-15\% & D-7\% & D-1\% \\
\hline Total Energy Consumption (TEC) [kWh] & 228.82 & $\triangle 0 \%$ & $凶 0 \%$ & $\triangle 0 \%$ & $凶 0 \%$ & D-15\% & $\triangle-7 \%$ & D-1\% \\
\hline Avg Vehicle Occupancy (AVO) & 3.13 & D-21\% & D-41\% & D-14\% & 凶 $23 \%$ & $D-18 \%$ & D-3\% & 区 $15 \%$ \\
\hline Transport Intensity (TI) $[\mathrm{km} / \mathrm{pax}]$ & 0.50 & $\mathbf{1 3} \%$ & 区 $28 \%$ & $\mathbf{x} 1 \%$ & $凶 0 \%$ & $D-13 \%$ & D-5\% & D-2\% \\
\hline Commercial Speed (Vc) $[\mathrm{Km} / \mathrm{h}]$ & 21.73 & $\times 3 \%$ & $\times 6 \%$ & D $-3 \%$ & 区 $6 \%$ & $\nabla-3 \%$ & $\square-1 \%$ & D-1\% \\
\hline \% Stopping Time (ST) & 46.88 & $D-1 \%$ & $D-1 \%$ & D-1\% & D-1\% & 区 $17 \%$ & 区 $8 \%$ & 区 $2 \%$ \\
\hline Operator Unit Cost (OUC) $[€ / \mathrm{pax}]$ & 1.04 & $\mathbf{1 2} \%$ & 区 $27 \%$ & $\times 1 \%$ & $凶 0 \%$ & D-2\% & $凶 0 \%$ & D-1\% \\
\hline \multicolumn{9}{|l|}{ SYSTEM-RELATED } \\
\hline Total Unit Cost (TUC) [€/pax] & 4.36 & $\times 0 \%$ & $\times 1 \%$ & $\times 7 \%$ & D $-5 \%$ & $\times 7 \%$ & $\times 6 \%$ & D-2\% \\
\hline Total Unit Cost (TUC) $[€ / \mathrm{pax}] \mathrm{AV}$ & 3.73 & $\nabla-2 \%$ & $D-4 \%$ & $\times 8 \%$ & $\nabla-6 \%$ & 邓 $7 \%$ & $凶 7 \%$ & $\nabla-2 \%$ \\
\hline
\end{tabular}

FIGURE 14: Summarizing table with FRF simulation outputs (for scenarios 1-3, percentage variations are reported with respect to Sc-base). 


\begin{tabular}{|c|c|c|c|c|c|c|c|c|c|c|c|}
\hline \multirow{2}{*}{ OUTPUT } & \multirow{2}{*}{$\begin{array}{c}\text { SC-base } \\
\text { base }\end{array}$} & \multicolumn{2}{|c|}{ SC-1 } & \multicolumn{2}{|c|}{ SC-2 } & \multicolumn{3}{|c|}{ SC-3 } & \multicolumn{3}{|c|}{ SC-4 } \\
\hline & & SC-1a & SC-1b & SC- $2 a$ & SC2-b & SC-3a & SC-3b & SC-3c & SC-4a & SC- $4 \mathrm{~b}$ & SC-4c \\
\hline \multicolumn{12}{|l|}{ USER-RELATED } \\
\hline \# tot Requests (NR) & 820 & $0 \%$ & $0 \%$ & $0 \%$ & $0 \%$ & $1 \%$ & $0 \%$ & $1 \%$ & $0 \%$ & $0 \%$ & $0 \%$ \\
\hline \% Walking Users (WLK) & 16.17 & $81 \%$ & $143 \%$ & $44 \%$ & $17 \%$ & $44 \%$ & $14 \%$ & $-5 \%$ & $-26 \%$ & $-31 \%$ & $-23 \%$ \\
\hline \% Accepted Requests (PAX) & 94.20 & $\mathbb{x}-1 \%$ & D $0 \%$ & 区 $-9 \%$ & 区 $-3 \%$ & 区 $-5 \%$ & $\times-2 \%$ & D $0 \%$ & ( $5 \%$ & D $6 \%$ & D $5 \%$ \\
\hline \% Rejected Requests (REJ) & 5.80 & Х $24 \%$ & D $-3 \%$ & $\times 141 \%$ & $\times 53 \%$ & 区 $80 \%$ & 区 $30 \%$ & D-1\% & D-87\% & D $-96 \%$ & [ $-80 \%$ \\
\hline \% Delayed Requests (DEL) & 0.04 & $-50 \%$ & D $-44 \%$ & D $-85 \%$ & 区 $424 \%$ & 区 $307 \%$ & \ $46 \%$ & D $-2 \%$ & D $-100 \%$ & D-100\% & D $-100 \%$ \\
\hline Avg Pre-trip Time (Tpt) [min] & 1.68 & D $-7 \%$ & D-12\% & $\times 85 \%$ & D $-78 \%$ & D-1\% & D-3\% & D-10\% & D $-15 \%$ & 区 $16 \%$ & 区 $32 \%$ \\
\hline Avg Walking Time (Twk) [min] & 2.27 & $-8 \%$ & D-14\% & D $-14 \%$ & $\times 3 \%$ & D-8\% & D-2\% & D $-8 \%$ & D $-4 \%$ & D-6\% & D-13\% \\
\hline Avg Waiting Time (Twt) [min] & 3.08 & $\mathrm{X} 9 \%$ & $\mathrm{x} 7 \%$ & D $-26 \%$ & 区 $47 \%$ & 区 $14 \%$ & $\times 12 \%$ & $\times 11 \%$ & D-18\% & D $-6 \%$ & Q $-5 \%$ \\
\hline Avg Ride Time (Trd) [min] & 6.38 & D-7\% & D $-26 \%$ & X $29 \%$ & 凶 $9 \%$ & D-1\% & 区 $6 \%$ & $\times 7 \%$ & D-15\% & D $-27 \%$ & D $-36 \%$ \\
\hline Avg Total Travel Time (T) [min] & 11.73 & $-3 \%$ & D-15\% & $\triangle 6 \%$ & Х $18 \%$ & 凶 $2 \%$ & 区 $6 \%$ & 区 $5 \%$ & D $-14 \%$ & D-18\% & D $-23 \%$ \\
\hline Avg Time Stretch (STR) & 2.00 & 区 $10 \%$ & $\times 16 \%$ & $\times 6 \%$ & $\times 16 \%$ & 凶 $17 \%$ & 凶 $9 \%$ & $\times 3 \%$ & D-12\% & D-14\% & D $-18 \%$ \\
\hline Avg User Disutility (Utot) [min] & 18.11 & $-7 \%$ & D $-20 \%$ & 区 $12 \%$ & \ $18 \%$ & 凶 $9 \%$ & $凶 7 \%$ & 区 3\% & D-19\% & D $-20 \%$ & D-22\% \\
\hline Passenger Unit Cost (PUC) [€/pax] & 3.08 & $D-2 \%$ & D-13\% & $\times 9 \%$ & X $19 \%$ & メ $8 \%$ & × $7 \%$ & $\times 4 \%$ & D. $-19 \%$ & D $-20 \%$ & $\Delta-22 \%$ \\
\hline \multicolumn{12}{|l|}{ OPERATOR-RELATED } \\
\hline Total Driven Distance (D) [Km] & 439.44 & D-14\% & $D-26 \%$ & D-7\% & D $-15 \%$ & $D-14 \%$ & D $-9 \%$ & D $-9 \%$ & \ $46 \%$ & Х $118 \%$ & 区 $280 \%$ \\
\hline Total Energy Consumption (TEC) [kWh] & 263.66 & D-14\% & D-26\% & D $-7 \%$ & D $-15 \%$ & D $-14 \%$ & D $-9 \%$ & D-9\% & D $-27 \%$ & D $-35 \%$ & 区 $14 \%$ \\
\hline Avg Vehicle Occupancy (AVO) & 3.70 & D-14\% & D $-36 \%$ & $\nabla-2 \%$ & $\times 31 \%$ & $D-2 \%$ & 区 $5 \%$ & $\times 10 \%$ & D $-45 \%$ & D $-73 \%$ & $-87 \%$ \\
\hline Transport Intensity (TI) [km/pax] & 0.64 & $\times 1 \%$ & $\times 2 \%$ & $\times 1 \%$ & D $-12 \%$ & D $-7 \%$ & D-6\% & D-11\% & 区 $39 \%$ & メ $105 \%$ & × $264 \%$ \\
\hline Commercial Speed (Vc) $[\mathrm{Km} / \mathrm{h}]$ & 23.06 & 区 $-3 \%$ & $\times-3 \%$ & $\mathrm{x}-3 \%$ & 区 $-4 \%$ & 区 $-4 \%$ & 区 $-4 \%$ & $\times-5 \%$ & D $4 \%$ & D $9 \%$ & D $13 \%$ \\
\hline \% Stopping Time (ST) & 39.56 & 区 21\% & 区 $39 \%$ & 区 $12 \%$ & $凶 21 \%$ & 凶 $20 \%$ & 区 $12 \%$ & $\times 12 \%$ & 区 19\% & 区 $52 \%$ & 区 $64 \%$ \\
\hline Operator Unit Cost (OUC) $[€ / \mathrm{pax}]$ & 1.19 & Х $14 \%$ & 区 $28 \%$ & 区 $7 \%$ & $D-1 \%$ & 区 $4 \%$ & \ $1 \%$ & D $-5 \%$ & 区 $35 \%$ & 区 $141 \%$ & 区 $387 \%$ \\
\hline \multicolumn{12}{|l|}{ SYSTEM-RELATED } \\
\hline Total Unit Cost (TUC) [€/pax] & 4.27 & $\times 2 \%$ & D-1\% & $\times 8 \%$ & X] $13 \%$ & $\times 7 \%$ & 凶 $5 \%$ & $\mathrm{x} 2 \%$ & D $-4 \%$ & 区 $25 \%$ & 区 $92 \%$ \\
\hline Total Unit Cost (TUC) [€/pax] AV & 3.57 & D-1\% & $\triangle-9 \%$ & X $8 \%$ & X $15 \%$ & X $6 \%$ & 区 $6 \%$ & $\mathrm{x} 2 \%$ & $D-16 \%$ & D $-12 \%$ & 凶 $5 \%$ \\
\hline
\end{tabular}

FiguRE 15: Summarizing table with DRF simulation outputs (for scenarios 1-4, percentage variations are reported with respect to Sc-base).

This is due to the regularity of the FRF service, which is higher compared to the DRF. On the opposite, when the demand is homogeneously distributed in origin/destination from/to the MRT station, a DRF service is to be preferred.

\section{Conclusions}

This article presented an agent-based model (ABM) for the mass rapid transit feeder design. Fixed-route feeder (FRF) and demand-responsive feeder (DRF) services have been compared to understand their attractiveness under different conditions, by taking into account both operator and user perspectives. The ABM reproduces a parametric synthetic environment where different variables related to demand, service area, and service configurations can be easily modified. The first set of scenarios allowed a comparison with the analytical model presented in Quadrifoglio and $\mathrm{Li}$ [18] finding a critical demand density that acts as a switching point between the two services. This was performed to show the effectiveness of the simulation model and the proposed insertion heuristic by reproducing the same scenarios and introducing new realistic constraints, allowing to find a demand density threshold.

The second set of simulations was performed to reproduce different use cases by changing the demand/service configurations while maintaining the same demand density, mimicking realistic scenarios of different transport services and land-use areas. The results of ten scenarios show that a demand concentrated near the MRT station improves the performance of both the DRF and FRF services with the DRF to be preferred due to lower total (user and operator) unit costs. Stretching the service area improves the performance of the FRF services because of the lower travellers' walking time, while a nonhomogeneous demand pattern may suggest adopting different service configurations (FRF of DRF) along the day. Finally, by increasing the DRF fleet while maintaining the same total capacity (i.e., using smaller vehicles), one can notice that there is no gain in terms of total unit cost since the increase in the operator cost is not compensated by an equivalent decrease of user cost. This could be changed by considering automated vehicles that would drastically reduce the operator cost.

In terms of practical implications, the results suggest that the DRF is to be preferred in TOD-like areas characterized by a high negative density gradient from the MRT station (Sc-1b), or in peripheral areas where station spacing is quite high (Sc-base). Vice versa, the FRF should be preferred in mono-functional land-use areas (e.g., residential or workplaces) during peak periods. Besides, the same transport operator might switch services along the day as the demand pattern changes over time, using an FRF during peak periods and a DRF during off-peak periods. This could be carried out 
using the same vehicle fleet and staff, just changing the operation parameters.

In summary, the proposed model can be used to optimize a feeder-trunk transit network, by using variables related to MRT network topology, its line and station spacing, and spatial and temporal demand pattern as inputs, and finding the optimal feeder operation as output. Our dispatching algorithm, based on insertion heuristics, involves three levels of exploration of the feasible solutions, that is, the set of vehicles that can serve the request, the set of locations where the request can be physically served, and the set of feasible insertions between two already scheduled stops. This approach has the advantage of consolidating passenger requests, reducing detours, and allowing for a higher shareability of the service. Moreover, it enables the transit operator to vary the flexibility of the operation from almost a door-to-door service to a point- or routedeviation service. We believe that such a dynamic procedure can be applied by real operators in real transit networks, providing good solutions without high computational burden, and it can be improved to deal with wider operating context.

This study comes with some limitations opening future research. First, the theoretical nature of the model, and the application to a synthetic case study, while making it generalizable, do not allow to formulate context-based practical implications. In this respect, the upgraded version of our model should consider the user-specific (e.g., gender, age, occupation) and mode-specific differences [46], which reflect the heterogeneity of user preferences regarding the different time components, the value of time, and the service fare. Also, applying the model to real case studies would imply devoting particular attention to the demand forecasting and user loyalty to the DRT service over time [47], two factors which are crucial to ensure a proper planning, operation design, and eventually the viability of the service itself. Accordingly, we would address the problem of travel demand uncertainty, relying on more data and use cases. Another attractive issue, which is currently poorly addressed in literature, is the evaluation of dynamic pricing schemes for flexible transit, which would help the service providers improve system performance, maximizing the profit according to the spatial and temporal variation in demand. Dynamic pricing strategies [48] can be included in more sophisticated ABMs, where negotiation mechanisms between the vehicle fleet and the users and among the vehicles themselves would be simulated. In future research endeavours, it will be interesting to compare the performance of DRF and of parallel FRF services that could be used to serve the service area with the same operation costs, reducing the walking time of users while increasing the headway. Finally, the impact of automated vehicles on service performance should be analysed more in detail to further explore the potential of this new technology to provide efficient feeder services.

\section{Appendix}

\section{A. Derivation of the Demand Density Function}

From a spatial perspective, the base demand density (in trips $/ \mathrm{km}^{2} \mathrm{~h}$ ) is modelled as a linear function $\lambda=\lambda_{0}-m x$, where $x$ is the horizontal distance from the terminal (in $\mathrm{km}), \lambda_{0}$ is the demand density at $x=0$, and $m$ is the slope that makes the values decrease. Let us denote with $\lambda L$ the as the demand density at $x=L$, with $\bar{\lambda}$ the average demand density (which occurs at $x=L / 2$ ) and with $\Lambda$ the ratio between $\lambda L$ and $\lambda 0$ (Figure 12). We obtain $m=(\lambda 0-\lambda L) / L$, $\bar{\lambda}=(\lambda 0+\lambda L) / 2$, and $\lambda L=\Lambda \lambda 0$. We can therefore express the demand function via the two parameters $\bar{\lambda}$ and $\Lambda$ as follows:

$$
\lambda=\frac{2}{1+\Lambda} \bar{\lambda}\left(1-\frac{1-\Lambda}{L} x\right)
$$

From Equation (A.1), we derive $\lambda 0=2 \bar{\lambda} /(1+\Lambda)$ and $\lambda L=2 \Lambda \bar{\lambda} /(1+\Lambda)$. The value $\Lambda=1$ represents the case where the demand is assumed spatially homogeneous throughout the service region; thus, from Equation (A.1), we obtain $\lambda=$ $\bar{\lambda}, \forall x$.

\section{B. Derivation of the Expected Value of the DRF Cycle Distance}

The expected cycle distance ECD for the DRF service, that is, the length of the round route, is given by the sum of a horizontal component (the vehicle movement from the left to the right and vice versa) and a vertical component (the deviations along the vertical direction to serve the passengers). The former derives from Section 4.2 of [18] and generalizes the result to the nonuniform demand assumption (Appendix C), whereas the latter derives from Section 4 of [49] and it is improved by a correction coefficient $\xi_{c}$ (Appendix D), which accounts for the spatial and temporal consolidation of multiple trip requests at the same virtual stop (i.e., served by the same vehicle at the same time). Assuming we divide the service area in a large number $N_{L}$ of segments of length $\Delta z=L / N_{L}$ and width $W$, we can express the expected cycle distance as follows:

$$
\begin{aligned}
& \text { ECD } \\
& +\xi_{c}\left[\frac{W}{2}+(n-1) \frac{W}{3}\right]
\end{aligned}
$$

Unlike the above-cited works, in our simulation model, backtrackings are allowed. In fact, let us imagine that the vehicle serves 3 requests $r_{i}(i=1,2,3)$ with coordinates $\left(x_{i}, y_{i}\right)$ and $x_{1}<x_{2}<x_{3}$. With the no-backtracking policy of $[18,49]$, the requests should have been served in the order $\left[r_{1} r_{2} r_{3}\right]$, but the dispatching algorithm (discussed in the next paragraph) could find that the order $\left[r_{2} r_{1} r_{3}\right]$ is a better solution even though it implies a minor backtracking movement.

\section{Derivation of the Expected Value of the Horizontal Component of the DRF Cycle Distance}

For a random request $r$, the probability that $x_{r} \leq z$, being $0 \leq$ $z \leq L$, is given by the ratio between the red trapezoid and the light-blue trapezoid (Figure 12), so that we derive 


$$
\begin{aligned}
& \operatorname{Pr}\left(x_{r} \leq t\right) \\
& =\frac{\lambda_{0}+\lambda_{z}}{\lambda_{0}+\lambda_{L}} \frac{z}{L} \\
& =\frac{2-(1-\Lambda)(z / L)}{1+\Lambda} \frac{z}{L} \\
& =\frac{2}{1+\Lambda} \frac{z}{L}-\frac{1-\Lambda}{1+\Lambda} \frac{z^{2}}{L^{2}},
\end{aligned}
$$

where $\Lambda$ is the ratio between $\lambda L$ and $\lambda 0$.

As in [18], the expected value of the horizontal component of the DRF cycle distance can be derived as follows:

$$
\begin{aligned}
& =\int_{0}^{L}\left\{1-\operatorname{Pr}\left[\left(\max \left(x_{r}\right) \mid r=1, \ldots, n\right) \leq z\right]\right\} \mathrm{d} z, \\
& =\int_{0}^{L}\left\{1-\prod_{r=1}^{n}\left[\operatorname{Pr}\left(x_{r} \leq z\right)\right]\right\} \mathrm{d} z \\
& =\int_{0}^{L}\left[1-\left(\frac{2}{1+\Lambda} \frac{z}{L}-\frac{1-\Lambda}{1+\Lambda} \frac{z^{2}}{L^{2}}\right)^{n}\right] \mathrm{d} z .
\end{aligned}
$$

Imagine dividing the length of the service area $L$ in an adequately large number $N_{L}$ of segments of length $\Delta z=L / N L$ (e.g., $\Delta z \approx 10 \mathrm{~m}$ ). Then, we can approximate Equation (C.2) as follows:

$$
=\sum_{z=1}^{N_{L}}\left[1-\left(\frac{2}{1+\Lambda} \frac{z}{N_{L}}-\frac{1-\Lambda}{1+\Lambda} \frac{z^{2}}{N_{L}^{2}}\right)^{n}\right] \Delta z .
$$

In the case of uniform demand density $(\Lambda=1)$, Equation (C.2) becomes

$$
\begin{aligned}
& E\left[\max \left(x_{r}\right) \mid r=1, \ldots, n\right] \\
& =L \frac{n}{n+1}
\end{aligned}
$$

as in [18].

\section{Derivation of the Correction Coefficient $\xi_{\mathrm{c}}$}

In Section 3.4, we described the set of feasible virtual stops associated with a passenger's origin or destination. In Figure 13, the scheme of how passengers can be potentially assigned to the nearest three stops is depicted: the red dotted arrows indicate the stops where a single passenger request can be served, whereas the green dashed arrows indicate the stops where the consolidation of more than one request can happen. We ignore in this phase, for computational simplicity, the possibility of having a fourth virtual stop, which is the nearest one already scheduled but not yet visited by the vehicle.

Look at the virtual stop $O$ in Figure 13: it is a potential stop for passengers $a, b$, and $c$, where their trip requests can be consolidated. In general, we can determine an "attractivity area" around each virtual stop (the light-blue area around stop $O$ in Figure 13) equal to $3 d_{g}^{2}$. Therefore, considering the whole service region of area LW, the probability for two random requests of being consolidated in the same stop is given by the following equation:

$$
p_{c}=\frac{3 d_{g}^{2}}{\mathrm{LW}}
$$

from which we derive the probability of no-consolidation for two requests: $p_{n c}=1-p_{c}$.

Let us consider the expected number of trip requests $n$ that a vehicle should serve along its route (see Equation (6)). Each new request $i+1$ has a joint probability of no-consolidation with respect to each of the $i$ already scheduled requests, $p_{n c}{ }^{2}$. Then, considering the $n-1$ requests after the first one, we can derive (The derivation of $\xi_{c}$ is based on the sum of the geometric series $\left.\sum_{k=1}^{n} r^{k}=r\left(1-r^{n}\right) / 1-r\right)$ the correction coefficient $\xi_{c}$, which takes into account the decrease in the expected cycle time due to the demand consolidation, which is given as follows:

$$
\begin{aligned}
& \xi_{c} \\
& =\frac{p_{n c}\left(1-p_{n c}^{n-1}\right)}{(n-1)\left(1-p_{n c}\right)} .
\end{aligned}
$$

\section{E. Results of the Second Set of Simulations}

The simulation outputs of the base scenario (Sc-base) and the percentage variations of the outputs of the other scenarios with respect to the Sc-base are summarized in Figure 14 (FRF service) and Figure 15 (DRF service).

\section{Data Availability}

All data used in this article will be made available upon request.

\section{Conflicts of Interest}

The authors declare that there are no conflicts of interest regarding the publication of this article.

\section{Acknowledgments}

The work was partially supported by the project "WEAKITRANSIT: WEAK-demand areas Innovative TRANsport Shared services for Italian Towns" (unique project code: E44I17000050001) under the programme "PRIN 2017", by the project of M. Le Pira "AIM Linea di Attività 3-Mobilità sostenibile: Trasporti" (unique project CODE CUP E66C180013890007) under the programme "PON Ricerca e Innovazione 2014-2020-Fondo Sociale Europeo, Azione 1.2 'Attrazione e mobilità internazionale dei ricercatori', and by the project "ADDRESS" under the University of Catania programme "PIACERI Linea 2". 


\section{References}

[1] M. Noussan and S. Tagliapietra, "The effect of digitalization in the energy consumption of passenger transport: an analysis of future scenarios for Europe," Journal of Cleaner Production, vol. 258, Article ID 120926, 2020.

[2] K. Gkiotsalitis and O. Cats, "Public transport planning adaption under the COVID-19 pandemic crisis: literature review of research needs and directions," Transport Reviews, vol. 41, no. 3, pp. 374-392, 2021.

[3] T. Storme, J. De Vos, L. D. Paepe, and F. Witlox, "Limitations to the car-substitution effect of MaaS. Findings from a Belgian pilot study," Transportation Research Part A: Policy and Practice, vol. 131, pp. 196-205, 2020.

[4] G. Ambrosino, J. D. Nelson, and S. Gini, "The pivotal role of Public Transport in designing the integration of mobility services and in operating MaaS offer: the concept of Shared Mobility Centre and the experience of Arezzo," in REAL CORP 2016-SMART ME UP! How to become and how to stay a Smart City, and does this improve quality of life? Proceedings of the 21st International Conference on Urban Planning, Regional Development and Information Society, CORP-Competence Center of Urban and Regional Planning, pp. 737-747, 2016.

[5] J. Brake, J. D. Nelson, and S. Wright, "Demand responsive transport: towards the emergence of a new market segment," Journal of Transport Geography, vol. 12, no. 4, pp. 323-337, 2004.

[6] EPRS, "Sparsely populated and under- populated areas," 2016, https://www.europarl.europa.eu/RegData/etudes/BRIE/ 2016/586632/EPRS_BRI(2016)586632_EN.pdf.

[7] L. Bisaschi, F. Romano, M. Carlberg et al., Research for TRAN Committee - Transport Infrastructure in Low-Density and Depopulating Areas, European Parliament, Policy Department for Structural and Cohesion Policies, Strasbourg, France, 2021.

[8] N. Giuffrida, M. L. Pira, G. Inturri, and M. Ignaccolo, "Addressing the public transport ridership/coverage dilemma in small cities: a spatial approach," Case studies on transport policy, vol. 9, no. 1, pp. 12-21, 2021.

[9] J. Wang, T. Yamamoto, and K. Liu, "Spatial dependence and spillover effects in customized bus demand: empirical evidence using spatial dynamic panel models," Transport Policy, vol. 105, pp. 166-180, 2021.

[10] M. Diana, M. M. Dessouky, and N. Xia, "A model for the fleet sizing of demand responsive transportation services with time windows," Transportation Research Part B: Methodological, vol. 40, no. 8, pp. 651-666, 2006.

[11] K. Winter, O. Cats, G. H. D. A. Correia, and B. V. Arem, "Designing an automated demand-responsive transport system: fleet size and performance analysis for a campus-train station service," Transportation Research Record: Journal of the Transportation Research Board, vol. 2542, no. 1, pp. 75-83, 2016.

[12] G. Currie and N. Fournier, "Why most DRT/Micro-Transits fail - what the survivors tell us about progress," Research in Transportation Economics, vol. 83, Article ID 100895, 2020.

[13] G. Inturri, N. Giuffrida, M. L. Pira, M. Fazio, and M. Ignaccolo, "Linking public transport user satisfaction with service accessibility for sustainable mobility planning," ISPRS International Journal of Geo-Information, vol. 10, no. 4, 2021.

[14] M. Fazio, M. L. Pira, G. Inturri, and M. Ignaccolo, "Bus Rapid Transit vs. Metro. Monitoring on-board comfort of competing transit services via sensors," in Proceedings of the 2020 Forum on Integrated and Sustainable Transportation Systems
(FISTS), pp. 292-297, IEEE, Delft, Netherlands, November 2020.

[15] M. Wei, T. Liu, B. Sun, and B. Jing, "Optimal integrated model for feeder transit route design and frequency-setting problem with stop selection," Journal of Advanced Transportation, vol. 2020, Article ID 6517248, 12 pages, 2020.

[16] B. Mehran, Y. Yang, and S. Mishra, "Analytical models for comparing operational costs of regular bus and semi-flexible transit services," Public Transport, vol. 12, no. 1, pp. 147-169, 2020.

[17] S. Mishra, B. Mehran, and P. K. Sahu, "Assessment of delivery models for semi-flexible transit operation in low-demand conditions," Transport Policy, vol. 99, pp. 275-287, 2020.

[18] L. Quadrifoglio and X. Li, "A methodology to derive the critical demand density for designing and operating feeder transit services," Transportation Research Part B: Methodological, vol. 43, no. 10, pp. 922-935, 2009.

[19] T. Garaix, C. Artigues, D. Feillet, and D. Josselin, "Vehicle routing problems with alternative paths: an application to ondemand transportation," European Journal of Operational Research, vol. 204, no. 1, pp. 62-75, 2010.

[20] M. E. Bruni, F. Guerriero, and P. Beraldi, "Designing robust routes for demand-responsive transport systems," Transportation Research Part E: Logistics and Transportation Review, vol. 70, pp. 1-16, 2014.

[21] N. Ronald, J. Yang, and R. G. Thompson, "Exploring comodality using on-demand transport systems," Transportation Research Procedia, vol. 12, pp. 203-212, 2016.

[22] S. Wang, G. H. D. A. Correia, and H. X. Lin, "Exploring the performance of different on-demand transit services provided by a fleet of shared automated vehicles: an agent-based model," Journal of Advanced Transportation, vol. 2019, Article ID 7878042, 16 pages, 2019.

[23] G. Calabro, G. Correia, N. Giuffrida, M. Ignaccolo, G. Inturri, and M. L. Pira, "Comparing the Performance of Demand Responsive and Schedule-Based Feeder Services of Mass Rapid Transit: An Agent-Based Simulation Approach," in Proceedings of the 2020 Forum On Integrated And Sustainable Transportation Systems (FISTS), pp. 280-285, IEEE, Delft, Netherlands, November 2020.

[24] J. Mageean and J. D. Nelson, "The evaluation of demand responsive transport services in Europe," Journal of Transport Geography, vol. 11, no. 4, pp. 255-270, 2003.

[25] M. Enoch, S. Potter, G. Parkhurst, and M. Smith, "Intermode: Innovations in Demand Responsive Transport," 2004, https:// www.researchgate.net/profile/Graham-Parkhurst/publication/ 37183508_INTERMODE_innovations_in_demand_responsive_ transport_final_report/links/5616ac2008ae1a8880031d6a/ INTERMODE-innovations-in-demand-responsive-transportfinal-report.pdf.

[26] M. Diana and M. M. Dessouky, "A new regret insertion heuristic for solving large-scale dial-a-ride problems with time windows," Transportation Research Part B: Methodological, vol. 38, no. 6, pp. 539-557, 2004.

[27] L. Quadrifoglio, M. M. Dessouky, and K. Palmer, "An insertion heuristic for scheduling mobility allowance shuttle transit (MAST) services," Journal of Scheduling, vol. 10, no. 1, pp. 25-40, 2007.

[28] S. Chandra and L. Quadrifoglio, "A model for estimating the optimal cycle length of demand responsive feeder transit services," Transportation Research Part B: Methodological, vol. 51, pp. 1-16, 2013. 
[29] Q. Tang and P. Du, "Study on accessibility of feeder lines with different geometric shapes," Journal of Advanced Transportation, vol. 2020, Article ID 4040252, 14 pages, 2020.

[30] Y. Zheng, W. Li, and F. Qiu, "A methodology for choosing between route deviation and point deviation policies for flexible transit services," Journal of Advanced Transportation, vol. 2018, Article ID 6292410, 12 pages, 2018.

[31] Z. Wang, J. Yu, W. Hao, T. Chen, and Y. Wang, "Designing high-freedom responsive feeder transit system with multitype vehicles," Journal of Advanced Transportation, vol. 2020, Article ID 8365194, 20 pages, 2020.

[32] D. Huang, W. Tong, L. Wang, and X. Yang, "An analytical model for the many-to-one demand responsive transit systems," Sustainability, vol. 12, no. 1, 2020.

[33] K. Shinoda, I. Noda, M. Ohta, Y. Kumada, and H. Nakashima, "Is dial-a-ride bus reasonable in large scale towns? Evaluation of usability of dial-a-ride systems by simulation," in Proceedings of the International Workshop On Multi-Agents For Mass User Support, pp. 105-119, Springer, Berlin, Heidelberg, August 2003.

[34] P. M d'Orey, R. Fernandes, and M. Ferreira, "Empirical evaluation of a dynamic and distributed taxi-sharing system," in Proceedings of the 2012 15th International IEEE Conference On Intelligent Transportation Systems, pp. 140-146, IEEE, USA, September 2012.

[35] J. Bischoff, M. Maciejewski, and K. Nagel, "City-wide shared taxis: a simulation study in Berlin," in Proceedings of the 2017 IEEE 20th International Conference on Intelligent Transportation Systems (ITSC), pp. 275-280, IEEE, Yokohama, Japan, October 2017.

[36] G. Cich, L. Knapen, M. Maciejewski, A. U. H. Yaser, T. Bellemans, and D. Janssens, "Modeling demand responsive transport using SARL and MATSim," Procedia Computer Science, vol. 109, pp. 1074-1079, 2017.

[37] A. Scheltes and G. H. A. D. Correia, "Exploring the use of automated vehicles as last mile connection of train trips through an agent-based simulation model: an application to Delft, Netherlands," International Journal of Transportation Science and Technology, vol. 6, no. 1, pp. 28-41, 2017.

[38] A. Araldo, A. D. Maria, A. D. Stefano, and G. Morana, "On the importance of demand consolidation in mobility on demand," in Proceedings of the 2019 IEEE/ACM 23rd International Symposium on Distributed Simulation and Real Time Applications (DS-RT), pp. 1-8, IEEE, Cosenza, Italy, October 2019.

[39] S. Oh, R. Seshadri, D. T. Le, P. C. Zegras, and M. E. B. Akiva, "Evaluating automated demand responsive transit using microsimulation," IEEE Access, vol. 8, Article ID 82551, 2020.

[40] A. Fielbaum, X. Bai, and J. M. Alonso, "On-demand ridesharing with optimized pick-up and drop-off walking locations," Transportation Research Part C: Emerging Technologies, vol. 126, 103061 pages, 2021.

[41] G. Inturri, M. L. Pira, N. Giuffrida et al., "Multi-agent simulation for planning and designing new shared mobility services," Research in Transportation Economics, vol. 73, pp. 34-44, 2019.

[42] G. Inturri, N. Giuffrida, M. Ignaccolo et al., "Taxi vs. demand responsive shared transport systems: an agent-based simulation approach," Transport Policy, vol. 103, pp. 116-126, 2021.

[43] N. Giuffrida, M. L. Pira, G. Inturri, and M. Ignaccolo, "Ondemand flexible transit in fast-growing cities: the case of dubai," Sustainability, vol. 12, no. 11, 2020.

[44] G. Calabrò, G. Inturri, M. L. Pira, A. Pluchino, and M. Ignaccolo, "Bridging the gap between weak-demand areas and public transport using an ant-colony simulation-based optimization," Transportation Research Procedia, vol. 45, pp. 234-241, 2020.

[45] U. Wilensky, "NetLogo," Center for Connected Learning And Computer Based Modeling, Northwestern University, Evanston, IL, 1999.

[46] Z. Li, K. Liu, and J. Wang, "Exploring observed and unobserved preference heterogeneity in choice behavior of demand responsive customized bus service," Journal of Urban Planning and Development, vol. 147, no. 1, Article ID 05020038, 2021.

[47] J. Wang, T. Yamamoto, and K. Liu, "Key determinants and heterogeneous frailties in passenger loyalty toward customized buses: an empirical investigation of the subscription termination hazard of users," Transportation Research Part C: Emerging Technologies, vol. 115, Article ID 102636, 2020.

[48] C. Lei, Z. Jiang, and Y. Ouyang, "Path-based dynamic pricing for vehicle allocation in ridesharing systems with fully compliant drivers," Transportation Research Procedia, vol. 38, pp. 77-97, 2019.

[49] L. Quadrifoglio, R. W. Hall, and M. M. Dessouky, "Performance and design of mobility allowance shuttle transit services: bounds on the maximum longitudinal velocity," Transportation Science, vol. 40, no. 3, pp. 351-363, 2006. 